Bojan Cop

\title{
ZUR HETHITISCHEN SCHREIBUNG UND LAUTUNG
}

\author{
Meinem Vater \\ Jos'ip Č op \\ $1883-1966$
}

D.

Die oben veröffentlichten ersten drei Kapitel (A-C)* haben deutlich gezeigt, dass die indogermanischen Unterschiede zwischen Tenues und Mediae, mit gewisser Einschränkung auch die zwischen Tenues und Mediae aspiratae, in der hethitischen keilschriftlichen Orthographie klar zum Ausdruck kommën und so das Fortsetzen der indogermanischen phonologischen Oppositionen im Gebiet der Verschlusslaute noch in der historischen Zeit mit voller, Sicherheit bèzeugt wird Es gilt nun sich nach den Verhältnissen bei den übrigen Isonsonanten in intervokalischer Stellung umzusehen, um aus dem Vergleich des Verhaltens beider Gruppen nützliche Schlüsse über Gründe und Grenzen der in Frage stehenden Erscheinungen zu ziehen.

In der Schreibung der spiranten, d. h. eines s-Lautes, der mittels der śzeichen bezeichnet wurde, und eines h-Lautes, weiter der Nasale $n$ und $m$, schliesslich der Liquiden $l$ und $r$ herrscht auf den ersten Blick eine so grosse W i $11 \mathrm{k}$ u $r$, dass keine richtigen Regeln aufgestellt werden können; dazu kommt, dass in der Ursprache keine Voraussetzung für eine solche Zweiteilung vorliegt. Doch kann auch hier eine geduldige, ins Einzelne gehende,

* Lingu. $5,1963,21 \mathrm{ff}$.

${ }^{58}$ Es ist wohl sehr unsicher, wie viele $h$-Laute das Hethitische besass; die Frage hängt nicht nư von den philologisch-graphischen spekulationen ab, sondern muss auch vom standpunkt der sog. Laryngaltheorie beantwortet werden. Da ich darüber noch zu schreiben denke und eine ganz kurze Behandlung dieser Frage, soweit sie den Unterschied zwischen den doppelt und einfach geschriebenen spiranten betrifft, auch unten im Kapitel E steht, kann hier nur soviel gesagt werden, dass m. E. das Hethitische mit der einfachen $(-h-)$ und der doppelten Schreibung $(-h h-)$ wohi denselben Unterschied bezeichnen wollte; wie er auch zwischen -š- und -ššs usw. bestand. Ob er phonologisch relevant war oder nicht, kann auch erst im Kapitel $J$ besprochen werden; phonetisch waren die so bezeichneten Laute sicher verschieden. Wenn ich hier von éinem $h$-Laute spreche, so geschieht das gerade aus phonologischen Grïnden, d. h. es ist $\mathrm{m}$. E. von vornherein von kombinatorischen Varianten $-h-$ und $-h h$ - zu sprechen. Denn augenscheinlich stehen sich diese Graphien bzw. die hinter denselben stehenden Lautungen niemals in Opposition gegentuber. 
umsichtige und vorsichtige Untersuchung des ganzen Materials nicht ohne Eirfolg bleiben; ich kann aus Raummangel jedoch nur recht wenige Gedanken über diese Frage äussern, hauptsächlich soviel, dass die in den Kapiteln A - C behandelten, auch schon selbst ganz rudimentär dargestellten' Probleme weitere Stützen und Beleuchtung erhalten.

Wir werden das.Verhalten der im vorigen Absatzigenannten Laute in den stellungen nach historischem e$\mathrm{nach} l \mathrm{angem}$ Vokal und vor - $w_{-}$, jedoch auch diese Fragen nur möglichst kurz, untersuchen.

I. Die Laute $s, h, n, m, l, r$ nach historischem -e und nach langem Vokal überhaupt:

a) nach historischem -e-:

1. -s- (geschrieben und umschrieben mit -šs) stellt vor uns das schwierigste Problem; denn nach historischem - e- scheinen sich die beiden Möglichkeiten, -š- und -šs, zunächst ohne erkennbaren Grund, geltend gemacht zu häben; vgl.:

a) mit zu erwartendem einfachem -š-:

(1) eš- isein«, zu idg. "es-;

(2) eš- usitzen«, zu idg. és-;

(3) hueš- »]eben«, hueša iȘpiegel», huešu- »lebendign, vielleicht zu idg. *wes- wverweilen, wohnen, ubernachten $;^{58} a$

(4) šeš- wruhen, schlafen«, zu ai sas-ti uschlafenu;

(5) šešarija iseihen, filtrieren«, zu alb. shosh »sieben« aus *sē-s-, C̆op, $R H A .13$, fasc. $57,1955,70$;

(6) weši- "Weideu, wešija nweidenu, zu idg. *wes- uschmausen", vgl. yor

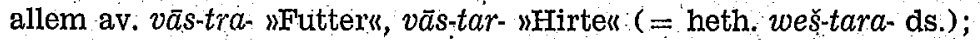

(7) hierher auch das idg. Suffix *es- in nepiš-nHimmeli, vgl, oben C I a) Nr. 3

(8)-(10) etymologisch unklar: heš-, Ablautform zu hašš- nöffnen ${ }^{58 \grave{b}}$ lala(k)ueša- "Ameisen, weš urija- iđrücken, bedrückeni; usw.;

(11) als Lehnwort aus dem Akkadischen (?) gilt teši- o. ähnl. nSommerhitzew,oder sErnte«;

${ }^{58}$ a Doch scheint diese Etymologie nicht mehr zuzutreffen; denn das luwische entsprechende Verbum múss huit- gelautet haben, wie das Adjektivum huitwalimlebendig« erweist; dabei ist es verhältnismässig gleichguiltig, ob man den Unterschied $-s-t-t / d-$ rein morphologisch auffasst (verschiedene Erweiterungen: Laroche, $R H A$.: 16, fsc. $63.1958,108)$ oder darin Wirkung eines rein phonetischen Gesetzes erblickt (doch ist Ottens, Z. gramm. u. lex. Best. a. Luv. 86 gemachter Vergleich mit šiw: „Gott«, šiwatt- iTagu: luw. tiwat- »Sonne(ngott), Tag« sicher unrichtig, vgl. Laroche a. a. O.); denn in ersterem Falle ist idg. *wes- morphologisch allzu fern, im zweiten kann man nicht um die Tatsache umhin, dass im Luwischen sonst immer $\therefore a$ - steht, wenn das Hethitische $e$ - aus idg. kurzem *-e-hat; wenn nun also huisvöllig $=$ luw. huit- ist, widerspricht heth. $-e / i-=$ luw. $-i-$ dem $-e-$ von idg. wes-. Vgl. auch Kronasser 54 f., 58 . Mehr an einer anderen stelle.

${ }^{58} \mathrm{~b}$ Vgl. dazu noch unten Pkt. c) Nr. 3 . 
B) mit doppeltem $-s ̌ s-:$

(12) kešser(a)- „Hand», zu gr. kheir, arm. dzerr-n, toch. A tsar, B šar, ai. hasta- as.;

(13) kišša- »kämmen» (auch kiša-!!), wozu kiššrari- neben kiš-ri- etwas aus Wolle, zu sl česa-ti, demnach gewiss mit -e- gesprochen;

(14) lešša-, lišša (auch liša-l!) isammeln, auflesen«, zu d. lesen, lit. lesu "picke aufu;

(15) wešš als Ablautform zu wašš- »bekleiden, bedeckèn, anziehen», zu idg. *wes- mkleidenu;

(16) hinter dem Präverb pe-: pe-ššija- nwerfen, stossen, verwerfen usw.u;

(17) hinter der Reduplikation: še-šsa šs-šš- veindrücken, prägen, siegelnu; vgl auch para-šešša »sich zerstreuen(??)«?

(18) dazu das recht häufige Suffix der Verbalsubstantiva und Nominalabstrakta -eššar, Gen. -ešnaš (auch -eššnaš), zu idg. ${ }^{*}-s e n-{ }^{*} s n o / \bar{a}$ - usw.; ${ }^{5 \varepsilon_{c}}$

${ }^{58} \mathrm{C}$ Zu diesem Suffix s. ausfuhrlich Kammenhuber in der oben Fn, 37 genannten Arbeit passim (s. Indices), sprachgeschichtlich vor allem $M I O .3,1955,357 \mathrm{ff}$. (etwas übertrieben scheint mir nur ihre Behauptung, die $r / n$-Flexion dieser Nomina sei erst im Hethitischen ausgebildet; wenn die anderen indogermanischen sprachen keine $r$-Form bieten, so ist das ja ganz in Einklang mit dem sonst beobachteten Schwinden der $r / n$-Flexion; vgl. noch Kammenhuber, Cor. Lingu. $99 \mathrm{ff}$.$) .$

Man soll jedoch beachten, dass es trotz aller Bedenken von Kammenhuber u. a. doch sehr feste Anhaltspunkte für ein uridg. *-ser-, *-sr- gibt, das in Austausch mit *-sen-, *-sn- stünde: wie es neben *-wer, *wen- in dem bekannten heteroklitischen Paradigma auch adjektivisches **-wero- $u$. ä. gibt, so kann man auch hier ein solches *-sero- und auch *-sro- anführen: das letztere sicher in dem keltisch-hethitischen, also uralten *naxH-sro- in heth. nahsar-att- )Furcht, Ehrfurchte, nahšar-ija»sich fürchtenı, nahšar-nu- nin Furcht setzen, erschreckeni und air. nār ubescheiden $;$; das erstere wohl wenigstens zum Teil im altindischen Suffix -sará-, das zwar ausserordentlich selten ist und in einem ganz sicheren Fall auch nicht in unseren Zusammenhang gehört, nämlich in der Ableitung vat-s-ará- »Jahr«; wo es sich nur um eine Erweiterung von vat-s-âa ds. handelt, $s$. Wackernagel-Debrunner, Altind. Gr. II 2, 925 (freilich sollte man bedenken, dass sich ein $r$-Suffix auch sonst in den Ausdrücken für Zeitbegriffe findet und dass wenigstens dieses auch in Austausch mit $n$-Suffixen steht, vgl. idg. *g'heimen- "Winter neben *g'heimer-u. a., s. Brugmann, Grdr. II 1,625), aber in mat-sará- vergötzend, berauschend" kaum von einem nicht nachzuweisenden *madas- "Rausch» abzuleiten ist, sondern das Wort wohl direkt auf die Verbalwurzel mad-geht, somit sein -sará- mit dem *-sro- in nah-sara usw. funktionell gleich ist. Das -e-, dem man im Hethitischen in fast allen unseren Abstrakta begegnet, ist eine weitere Schwierigkeit, vgl, Kammenhuber, MIO. 3, 1955, 357. Es ist für unsere Zwecke eben die Frage nach dem Ursprung dieses - $e_{-}$ sehr wichtig, da ja gerade dessen Quantität im Vordergrund steht, wie vor allem aus den Ausführungen am Ende des vorliegenden Kapitels hervorgeht. Man kann vielleicht folgenden Ausgangspunkt als den wahrscheinlichsten annehmen: unsere 'Ursprache kannte eine sehr ṕroduktive Gruppe der Verbalnomina mit Suffix *-es-,

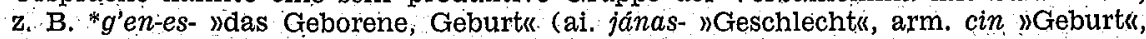
gr. génos »Geschlechti, lat genus ds.) zu *g'enè- verzeugen«, vgl. dazu Brugmann, Grdr. ${ }^{2}$ II 1, 514 ff.; im Hethitischen ist diese Bildung im allgemeinen sehr stark ausgedrängt worden; vgl. Kronasser 326 ff.; bes. 328 . Dennoch lässt sich von den hethitischen Bildungen wenigstens éine anfuhren, die ganz klar als sekundär angesehen werden muss : kutreš (und kutriš) »geringe Anzahl, Kürze« (der Jahre). Dies Wort, wenn es indogermanisch ist, kann keineswegs primär sein, denn eine Wurzelform *kutr- ist für das Indogermanische, auch in etwaiger anderer Ablautsstufe, un- 
(19) hierher auch das Suffix der Iterativa-Durativa $-(e) s ̌ s a-:^{58 d}$ ešša- wwirken, schaffen «, halżěšsa i (wiederholt) rufen, nennen, lesenu, mešša- iwachsen, gedeihenu, warrešsa- whelfen, zu Hilfe kommen", wohl mit Nr. 20 zusammenhängend: ${ }^{50}$

möglich; es muss demzufolge von einem Adjektivum *kutra- ikurzu auf direktem Wege ausgegangen sein oder aber ist eine $Z$ wischenstufe verbalen Charakters, etwa ein *kutrā- "gering machen, verkürzen, einschränkenu (oder intransitiv), anzusetzen. Auf jeden Fall aber ist vor uns ein Abstraktum mit suffixalem Element eš das ebenso an die nominale oder verbale Grundlage getreten war wie später das alleinherrschende -eššar. Anderseits muss man bei einigen Verbalstämmen einen Wandel - $\bar{a} j e-$ bzw, - $\bar{a} i$ - (nach Abtrennung von thematischem $-e-$ ) $>-e$-annehmen, wenn an solchen Verbalstamm ein mit $-s$ - beginnendes Suffix trat: zum Präsensstamm $h a t r a ̈ j(e)$ - uschreiben entstand so einerseits Iter. hatre-šk-, anderseits das Verbalabstraktum hatre-šsar (wobei es nicht-behauptet werden soll, dass gerade dies. Wort die allererste von derartigen Bildungen ist); gab es nun in einem solchen Formensystem das dem ganzen System zugrundeliegende Nomen, das denominative Verbum und die beiden $s$-Ableitungen, die auf -eš und die auf -eššar, so konnten verschie. dene Assoziationen entstehen, auch zwischen dem Grundstamm und dem Abstraktum eššar; da dieses aber unter dem Einfluss der Bildung auf blosses -eš-

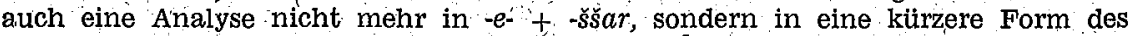
Grundstammes (nominalen oder verbalen) + - -eššar zuliess, so löste sich nun -ešsar als ein einheitliches Bildungselement áb. Die Entwicklung war demnach:

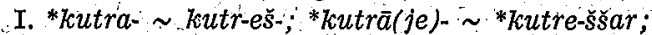

II. *kutra- *kutre-ššar; *kutr-eš- + *kutre=šs̆ar;

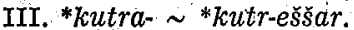

Dass es aber auch schon im Urindogermanischen eine Suffixvariante mit kur. zem $-e$ vor dem -s- gab; d. h. ein ${ }^{*}-e-s e r / n-b z w$. dessen thematisierte Formen wie ${ }^{*} e-s n o / \vec{a}-$ usw., beweisen u. a. die uralten vedischen Bildungen vadh-asná- iGeschoss (des Indra) \& zu vadh- whauen, schlagenu und karä-sna- "Vorderarmi neben kara"Handu, weiter lit. esnis, z. B. in mökesnis "Zahlungu, ai. -asnu- in vadh-asnuiSchützer usw., vgl: Wackernagel-Debrunner, Altind. Gr. IT 2, 927, \$ 766 a und 930, $\$ 767 \mathrm{c}$; Brugmann, Grdr. II 1, 282, 289. Das so ständige - $e$ - in unserem Suffix hat demnach feste Anhaltspunkte in seiner Vorgeschichte; mehrere Quellen gibt es auf jeden Fall für kurzes - $e$ - und diese Erkenntnis ist für uns in der oben erwähnten Hinsicht recht willkommen.

${ }^{58} \mathrm{~d}$ Die geringe Anzahl solcher Bildungen verbietet uns, genau über die Herkunft des -e- zu urteilen; in halze-šs̆a- sowie in e-šsa- wird es zum Grundstamm gehörén (urheth. *halt $\bar{e}_{-}{ }^{*} j \bar{e}-$ ), ebenso in $m e-s ̌ s a-$, wo man ursprünglichen Diphthong vor sich hat (*mëi- mit Verkürzung des Diphthonges vor -šs- in der Fn. $58 \mathrm{c}$ angegebenen Weise?) oder mit ebenfalls làngvokalischer stammform auskommen kann (*me-); in warre-šša kann man von warrät- oder von *warräje-auskommen, in beiden Fällen muss man aber die ebẹn genanntè Verkürzung vor -šs̆- annehmen. Doch kann man angesichts des historischen Zusammenhanges mit $\mathrm{Nr}$. 20 kaum übersehen; dass auch in dem unter Nr. 20 angefuhrten Suffixe ein - $e-+-s s-$ steht, wo aber kaum angenommen werden kann, dass in diesem - $e$-alte Länge bzw. alter Dipḥtong fortlebt. Mann muss demnach annehmen, dass unser iterativ'duratives $-(e) s ̌ s-a$ eine Erweiterung mit Themavokal - $a$ - von diesem inkohativen -ešs darstellt; von dem letzteren wurde auch das doppelte -šş ủbernommen, anfangs wohl auch das kurze - $e$, das aber wenigstens zum Teil bei vokalischen Grundstämmen dem langen vokalischen bzw. diphthongischen Auslaut, jedoch unter Beibehaltung des doppelten -šš-, weichen musste.

${ }^{59}$ Die Geschichte des bekannten indogermanischen suffixes *-sk'e/o- in verschiedenen indogermanischen sprachen macht es sehr wahrscheinlich, dass ähnliche funktionelle Verschiebungen auch in unserem Fall eingetreten sind, zumal beim 
(20) auch das Suffix der intransitiven Verba auf eš- wird vor vokalischen Endungen -ešš- geschrieben, zum idg, aoristischen *-s- auf verschiedenen Grundlagen (von Stämmen auf $*-e$ usw.); $;{ }^{59}$

(21) vgl. noch takkešš-anzi zu takš- izusammenfügenn, wo es sich um ein ablautendes Suffix *-es-/-s- handelt; 59

(22)-(26) etymologisch unklar: ,eššari- neben ešri- "Wollvliessu, ${ }^{60}$ heššalla(aber hiššlla- mit Glossenkeil!) etwa nins Auge fassen», šeššar "BBieru, šešši"Unterlassung" mit šššijant isunberlihrt", endlich das vielleicht ein suffixales -šš- enthaltende hanešša- ein Gefäss; ;00a

(27) vereinzelte bzw isolierte Fälle im sonst nach a) geschriebenen Paradigma: eššantari vơn eš- usitzenu, šeššir von šeš- uruhen, șchlafenu;

2. $h$ - ist in dieser Stellung immer einfach geschrieben; die Fälle, die hierher gehören, sind:

(28) mehur "Zeiti, zu idg. "mê- "messen«; ${ }^{* 0}$

(29) šehur "Urin«, zu sl. sbcati "pissen« usw.;"

(30) weh- isich drehen, sich wenden; sich bewegen, umherstreifenu, zu idg. * wejo- idrehen, biegenu; ;

(31) als Interjektion muss angesehen werden ehu nauf, herbei, komm!॥;

(32) hinter dem Präverb pe-: pe-hute- whinschaffen, hinführen«, Hinterglied zu C I Nr. 11, urspr. "pe-wete-;

Übertritt einer Formation der mi-Konjugation in die $h i$-Konjugation schon prinzipiell ein Funktionswechsel zu erwarten war. Unnötig ist dann die Annahme luwischer Herkunft bel Friedrich, Heth. El. $\mathrm{I}^{2} \$ 141$ d. Vgl. (ganz anders) Laroche, $B S L$. $53 / 1,1957 / 58,196 \mathrm{f}$, der mit Sturtevant an aoristische Herkunft unseres -šš- denkt, was jedenfalls nicht weit von unserer Erklärung abliegt.

${ }^{59}$ a Vgl. Pedersen, Hittitisch 95; dazu Fn. 59.

${ }_{\text {5o }}$ Eine ganz ähnliche Flexion soll nach Pedersen, Hittitisch 172 aus den Verhältnissen bei mauššs vf́alleni (Part: mušant-) erschlossen werden; das jügere Part. mauššant- und das Inf. I mauššwanzi wären demnach aus *mawe šuwanzi entstanden. U̇ber die Etymologie cop, $K Z .74,1956,226 \mathrm{ff}$.

60 Die Etymologie voń Benveniste, $B S L .50 / 1,1954, \because 42 \mathrm{f}$. (zu gr. érion "Wolle» usw.) ist lautlich unmöglich; dagegen Neumann, $K Z .75,1957,89$ f., wohl ganz mit Recht.

${ }^{60}$ a Zu han- uschöpfenผ?

${ }^{\circ} \mathrm{b}$ Freilich ist diese Etymologie nicht über alle Zweifel erhaben; man wird sie wohl einmal mit einer besseren ersetzen müssen.

${ }^{61}$ Laútlich sehr/schwierig, daher besser abzulehnen, wie auch Kammenhuber, Cor. lingu. 104 Fn. 28 tut; aber wenn sie als Ersatz dafür an idg. *sē- isäenu (nach Sturtevant) denkt, so scheint sie mutare quadrata rotundis und vor bedeutungsgeschichtlichen Schwierigkeiten Augen zu verschliessen. Man wird schon wieder neue Ftymologie suchen müssen, die aber nicht notwendigerweise auf vollständig verschiedene Wurzel führt. Mehr anderswo:

${ }^{61}$ a Das hethitische Verbum stellt demnach ein idg; *weiH- dar; mehr darüber an einem anderen Orte:

62 Allen Laryngalisten zum Trotz erweist das gegensätzliche $u$-wate- eine ursprachliche Wurzelform ohne Laryngal im Anlaut; $h$ - in pe-hute- muss demnach als erst auf dem hethitischen Boden entwickelt - hiatustilgend o. dgl - angesehen werden; man muss bedenken, dass $\alpha$ ) im Hethitischen die Lautfolge $w+$ Vokal sehr oft zum blossen Vokal $u$ wird, $\beta$ ) dass ein * pé-wete- demnach zu *pe ute- wurde, es 
(33) etymologisch unklar: ehurati- iPfropf aus Wolle» mit dem Verbum ehuràa $\bar{a}$ - uverstopfen«;

(34) sicher churritisch ist šehelli-, «Reinheit», wahrscheinlich ebenso šehelliški wKorb o. ähnliu;

(35) es gibt nur éine sichere Ausnahme von dieser Regel: die 1. Sg. auf -e-hhi, -e-hhun der Verbalklasse II $2 \mathrm{~b}$ : ne-hhi, ne-hhun von nāi- »lenken, leiten usw"; sie ist aber in Wirklichkeit kaum gefährlich: durch Systemzwang musste das hinter dem Stammauslaut -e (älter -äi-!!) gefährdete doppelte $-h h$ gehalten oder vielleicht erst wieder neu hergestellt werden;

3. -n- kommt nach -e- hauptsächlich einfach geschrieben vor, es gibt nur sehr wenige Ausnahmen; für regelmässige Schreibung, die etwa in 25 Grund. wörtern vorkommt, gebe ich nur eine kleinë Auswahl:

a) mit zu erwartendem einfachem $-n=z$. B.:

(36) genu iKnie», zu idg. *g'enu, *g'onu ds.;

(37) mene "Wange, Gesicht»; zu idg. *men- nemporragen«, vgl. lat. mentum "Kinnu; weiter idg. *mono- usw. "Nacken, Hals";

(38) Pronominalbildungen wie eni uder (eben) erwähnte», eniššan uso, in der erwähnten Weise», apeniššan ds.; ${ }^{63}$

(39) zena- sHerbstu ist mittels eines Suffixes -na- von zejari ner kocht (intr.) « abgeleitet, vgl. zur. Bedeutung ai. pacyate »kochen; reifen«, čop, $\check{Z} A .6$, $1956,42,49$

(40) ein Suffix ena steckt sicher $u$. a. in arahzena- mumwohnend, benachbartw von arahz(a) uringsum, ausserhalb», idg entweder "e/oino-oder (besser)*eeno-, *eno-; ${ }^{64}$

(41) - (42) hierher gehören auch die beiden Personalendungen 1, P1. -weni mit der Variante -meni und 2. Pl. -tteni; die sicher erst hethitische (bzw. anatolische) Neuschöpfungen sind;

aber nicht mehr weiter zur Kontraktion von - $e$ - $u$ - kommen konnte und $\gamma$ ) dass in *u-wete- das vorausgehende $u$-es verhinderte, aus *-we-auch hier *-u- werden zu lassen.

63 Die bekannte Deutung von eni, die Pedersen, Hittitisch 62 gegeben hat (zu lat. é $n$, gr. $\bar{e} n, \bar{e} n \bar{l}$ dè »siehe $d a !()$, ist sehr verlockend und vorläufig sicher das beste, was dariber gesagt wurde; doch erweckt starke Bedenken eine Parallelbildung im Luwischen: Laroche, $R H A$, 16, fasc. $63,1958,87$ (nach dem teilweisen Vorgang von Meriggi) erkennt als Iuwischen Aquivalent von heth eni ein zani, das nach ihm mittels eines suffixes - $n i$ aus dem Stamm $z a$ - wdieserı, erweitert worden ist; ganz so wie auch das hethitische e-ni; dabei muss man in Betracht ziehen, dass die Entsprechung heth. $e=$ luw. $a$ doch wohl nur fü idg. kurzes * $e$ gilt, nicht aber für die entsprechende Länge, so dass jđ̣g. * $\bar{e} n$ ausgeschlossen wäre; auch ist es kaum zu erwarten, dass sich aus rein hethitischem Material eine Analyse $e-n i$ ergeben konnte, die ja für die Nachbildung ape-niššan notwendig war; schliesslich ist die Schreibung zannin bei Laroche a. a. O. bemerkenswert, da sie zu denjenigen Fälien stimmt, die im Hethitischen ein aus idg. kurzem *-e-entstandenes historisches -e und einen unmittelbar folgenden einfach geschriebenen Konsonanten, im Luwischen dagegen - $a$ - und doppelt geschriebenen Konsonanten aufweisen, s, Kapitel F!

${ }^{4}$ Weiteres unten im Kapitel F. 
$\beta$ ) mit doppeltem $-n n$ - nur:

(43) hinter dem Präverb pe-: pe-nna- i(hin)treiben«;

(44) hinter dem Präverb ze-: ze-nna- ibeendigen, erledigen usw.";

(45) hinter der Reduplikation: ne-nna- (vereinzelt 3. P1. nennijanzi) als Nebenform von nanna- streibenu;

(46) kuenn- als eine der Stammformen von kuen- uschlagen, erschlagen, töteni (Präs. 1. P1. kuennummeni, 2. Pl. kuennatteni, 3. Pl. kuennanzi, Prät. 2. Sg. kuinnešta, 1. Pl. kuinnummen, 3. Pl. kuennir, Imper. 2. Sg. kuenni, Part. kuennijant, Verbalsubst. Gen. kuennumaš, Inf. I kuennummanzi, Iter. Kuennešk-) wird verschiedentlich erklärt; Friedrich, HW. 113 fasst diese Flexion als analogische Umbildung auf; Sturtevant, $C G r^{2}{ }^{2} 28,122,134$ sieht darin eine Erweiterung von kuen- mit einem Suffix - na- bzw. - n-ija- was Kronasser 21 Fn. 1 akzeptiert; jedenfalls ist Friedrichs Erklärung vorzuziehen, denn Beeinflussung vor allem durch zenna, womit kuenna- reimt, ist ganz natürlich;

4. - $m$ - kommt recht selten nach - $e$ - vor, aber in viel gebrauchten Wörtern; es wird nur einfach geschrieben, von wenigen sporadischen Fällen abgesehen:

(47) gem-i (Dat. -Lok.) vim Winterı, geman-ija- süberwinternu, zu idg. "g'hjem-bzw. "g'heim- "Winter"; im ersten Falle ist gemi = lat. hieme; das Verbum dagegen wohl vom $n$-Stamm im ai. Lok. hêman, gr, kheima "Winter"; ${ }^{65}$

(48) w-emija- ifinden, treffen, antreffenu, vielleicht $\mathrm{zu}$ idg. "em- mehmenu;

(49) hinter der Reduplikation: me-ma- usprechen mit memijan- uRede, Wort usw:《, zu idg. *men- wdenken, geistig erregt sein", Čop, Lingu. 4, $1961,57 \mathrm{ff}$.;

(50) hinter der Reduplikation: me-mal "Grütze«, zu idg. *mela szermalmen, mahlen $; ;^{65 a}$

(51) vereinzelte Fälle mit -mm- innerhalb des regelrecht geschriebenen Paradigmas; memmai, memmaš von mema- isprechen «, memmal von memal "Grütze";

5. $l$ ist nach $e-$ in etwa 30 Wörtern anzutreffen, ${ }^{65} \mathrm{~b}$ davon etwa 25 Fälle mit regelrecht einfach geschriebenem $-l$, nur 4 Wörter und éine Form mit doppeltem $l l$; die ersteren gebe ich nur in Auswahl:

65. Die Nebenform des Dat.-Lok. gimmi kann nicht gegen unsere Regel sprechen; denn das Paradigma dieses Wortes muss im Hethitischen einst mehrere Ablautformen enthalten haben; wie ja derartige Fälle auch sonst bei altererbten und viel gebrauchten Wörtern' anzutreffen sind: $k i r^{\prime}=/ k e \bar{r} /$ "Herz , Gen. kardijaš usw. (ISronassers Ansicht S. 25, dass es sich hier um die Neigung, e in a umzuwandeln, handelt;-wird schon durch die Verteilung beider Vokalisierungen widerraten); war es dem avestischen gleich, wo es im Nom. zyd̊ aus * $g^{\prime} h j o \bar{o}(m)-s$, im Gen, zim-o aus *g'him-es heisst, so missen auch im hethitischen Paradigma beide Ablautformen, dazu aber auch noch die im lat hiem- erhaltene, bestanden haben; im Lok. muss es also ${ }^{*} g^{\prime} h j e m$ i, im Dat. * $g^{\prime} h i m$-ei gegeben haben; aus letzterem dann gimmi, insoweit natürlich auf die vereinzelte Schreibung uberhaupt verlass ist; dass aber *g'him- wohl wirklich einst auch im Hethitischen bestand, erweist das stets mit Geminata geschriebene gimmant- "Winteri, das aus einer besonderen Ablautform, und zwar aus der Schwundstufe, mit ant- erweitert ist, vgl, zu solchen Bildungen

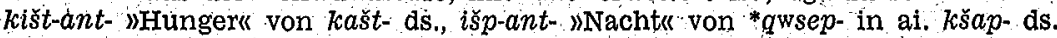


a) mit zu erwartendem einfachem $z$ - z. B:

(52) milit "Honigu (zu lesen melit), zu idg. *melit ds.; ${ }^{65} \mathrm{c}$

(53) hierher das Nominalsuffix -èl: hurk-el "Greuel«, Gen. hurkilaš u. a., zu idg. * *elt-;

(54) ebenso -zel: šarnik-zēl "Sühne, Entschädigung,. Busse», Gen. šarnikzilaš u. a., zu idg. *-tēt-;

(55) vom Pronominalsuffix -e-la iselbst» wurde oben im Kapitel A, Nr. 27, gesprochen;

B) mit doppeltem $l l-$ :

(56) arha huellä, sentschluipfen, sich entwinden, sicher mit huwäi- bzw. hüja- Hlaufen, fliehen, entkommen« zusammenhängend und wohl auf einem vorhistorischen "hwej-alla- (mit so häufigem $l$-Suffix) beruhend;

(57) hierher die Endung der 1. Sg. Imper. ellu, z. B. piške-llu von piškswiederholt geben", statt des üblichen -allu nach dem Stamm piške- bzw, peške-, vor allem 2. Sg. Imper. peški (zu lésen peske) umgeformt;

(58) etymologisch unklar: wellu- "Aue, Wiese»; ${ }^{65 \mathrm{~d}}$

(59) sicher churritisch ist sehelli „Reinheit» mit Zubehör, s. Nr. 34, und so wohl noch einige andere Wörter; ;se

6. $-r$ kommt nach $e$ - fast ausschliesslich in einfacher Schreibung vor; etwa in 15 Fällen, unten in Auswahl; nur sporadisch doppelte Schreibung:

a) mit zu erwartendem einfachem $-r$ - z. B.:

(60) išmeri- "Zaum, Zügelı, zu gr. smèringes: plektai, seirai, usw., čop, SlR. Lingu. 9, 1956, 37 ff.;

(61) kuer- sschneiden", vgl. 3. P1. kuerir,-mit A. Š̀ kuera- „Feld, Fluri, zu idg. " $q$ wer- ischneiden";

(62) peruna «Felsi, zu ai. parvata- iBergi;

(63) piran "vorn, voran, vor" (zu lesen peran), zu ai param "hinaus über", gr.pérāi $n)$ wdarüber hinaus», osk. perum »ohne«;

(64) werija- urufen, nennen usw.i, zu idg. *wer- wfeierlich sagen, sprechen«;

$65 \mathrm{a}$ Z. B. bei Sturtevant, $C G r r^{2} 68$

${ }^{45} \mathrm{~b}$ Die weitgrösste Gruppe davon bilden wohl Wörter, die mit den Suffixen -el- und zel-versehen sind. Einige von diesen Ableitungen sind für uns noch nicht erkennbar, da Grundwörter fèhlen. Vgl. Cop, SlR. Lingu. 9, 1956, 19 f. zu einem *kapp-el , MZornu.

${ }^{6 c}$ Das Adjektivum maliddu-, miliddu- usüssi ist wohl $/$ mlitt-u-/, zu lesen, enthält demnach schwundstufige Wurzel wie gr. blitto $\rightarrow z$ zeidle« aus * mlit-jō. Es ist also nicht gegen unsere Regel auszunutzen.

${ }^{65} d$ Man braucht nicht allzu nervös zu sein, wenn man ein -ll- in éinem etymologisch unklaren Wort vorfindet; denn gerade diese etymologische Unklarheit ist derjenige Umstand, der jedem logisch Denkenden Möglichkeit in die Hände gibt, die Ausnahme in der Schreibung des $l$-Lautes auf die Rechnung eines unbekannten phonetischen Faktors bzw. Wandels zu verlegen. Tatsächlich kann sich bei doppeltem $-l l$, auch' $\mathrm{um}$ Assimilation einer $l$-haltigen Konsonantengruppe handeln, $z$. B. ${ }^{*}-l n$ - oder ${ }^{*}-n l$-, *-ls- oder *-sl-, sogar *-nsl-, *-rl- usw. Rechnet man mit ${ }^{*}-s l$, dann könnte man an ein ur'spr. *wes-lu "Weide» denken, zu *wes- oben Nr. 6.

${ }^{6} \theta \mathrm{Vgl}$. huššlli- neben huššili- "Lehmgrubè? Fremd ist wohl sicher auch ellijanka neben illijanka-, illujanka- "schlange, Drache«. 
(65) werite- "sich ängstigen", zu lat. vereor wverehre, fürchte»;

(66) hierher auch das idg. Gegensatzsuffix *-ero- in kattera- wunterer";

$\beta)$ mit doppeltem -rr- nur:

(67) merrant-, Part. zu mer- vverschwinden, verlorengehen, absterbeni, zu idg. *mer- usterben";

(68) vereinzelt (vielleicht so auch Nr.67?) im sonst nach $\alpha$ ) geschriebenen Paradigma: kuirri von kuer- ischneiden", katterraš, katterriš, katterrahta, - katterrahhir von kattera- wunterer";

7. erwähnt sei noch, dass im Sandhi vor den enklitischen wörtern unsere Laute sehr oft doppelt geschrieben werden, vgl. ammell-a sund meiner, und von miri, šerr-a. wund darauf".

Betrachten wir nuin nur die echt hethitischen Fälle mit doppelt gescriebenem $-n-,-m-, r,-r$, so bekommen wir das folgende Bild:

hinter dem Präverb: pe-nna- Nr. 43, ze-nna- Nr. 44, beide ganz regelmässig;

hinter der Reduplikation: ne-nna- Nr. 45, vielleicht ganz sporadisch, unter dem Einfluss von na-nna-, nuir sporadisch me-mma- und me-mmal Nr. 51; Vgl. Fn. 152!

im Rahmen des Verbalparadigmas; wo verschiedene analogische Regelungen und Ausgleichungen, auch schriftliche, vorgekommen sein dürften: kuenn(a)- Nr. 46 (nach kuen-zi' und zenna), merr-Nr. 67 (nach mir-zi), kuirrNr. 68 (nach kuer-zi, kuir-zi);

ganz ähnlich im Sandhi: ammell-a (nach ammel), šerr-a (nach šer) Plkt. 7;

in der Verbalendung, wo Verschleppung von anders vokalisierten Formen zugrundeliegt: piške-llu (nach bzw. aus danebenstëhendem * piška-llu) Nr. 57;

aus ähnlichem Grunde wie der vorige Fall, da -e- erst durch Kontraktion zustande kam: huellö- Nr. 56.

Von den $h$-Fällen könnte als echt m. E. nur weh- Nr. 30 angesehen werden, ${ }^{65}$ wd die Verhältnisse ganz so wie bei anderen, eben behandelten e-haltigen Wörtern liegen; ${ }^{67}$ andere $h$-Fälle können sekundär entwickeltes $h$ haben, sind also keine Zeugen für Prozesse, die in der Ursprache ihre Anfänge haben; aber der einzige Fall mit -hh-, die Verbalformen auf -e-hhi, -e-hhun, ist schon wieder echt ,stellt freilich ein weiteres Beispiel von analogischer Umbildung unter dem Systemzwang dar.

Fasst man nun die eben gewonnenen Ergebnisse kurz zusammen, so erhält man eine sehr einfache Lösung: In ter rok a lis ches $-h-,-n-,-m-,, l-$ und -r wird nach historischem e regelrecht einfach geschrieben, nur nach den Präverbien pe- und ze- wird doppelte Schreibung durchgefuhrt; alle anderen Fälle mit doppelt geschriebenem -hh usw. sind sekundär, entweder a nalogisch nach anders vokalisierten Parallelformen durch-

66 Zur schwierigen Frage über die "Laryngale» im Hethitischen vgl. Fn. 58 und unten im Kapitel E.

67. Das Wort enthält in seinem - $h$ - ein wirklich gesprochenes und gehörtes Phonem, das auch etymólogischen Wert hat, $d$. $h$. aus einem ursprachlichen Phonem entstanden ist, s. Fn. 61 a. 
gefuhrt, oder sogar so dünn gät, dass se ohne wissenschaftlichen W e r t s ind.

Ganz anders istes um -s-bestellt: hier ist die einfache Schreibung beinahe bei ebenso vielen wörtern durchgefuhrt wie die doppelte; und eine genaue Ratio für die Häufigkeit der Jetzteren ist auf den ersten Blick kaum herauszuschälen; nur éines kann auf Grund weiterer Untersuchungen über den Ursprung des vor-hergehenden e-Lautes schon hier gesagt werden: die Doppels chreib. ung des s-Lautes kommt nur nach ursprunglich kurzem *e- vo r ! Weiter im letzten Abschnitt des vorliegenden Aufsatzes.

Interessant ist die eben beruhrte Frage, aus welcher ursprach. lichen Vokalform sich das vor den fraglichen sechs Konsonanten stehende historische e- entwickelt hat; man bekommt das folgende Bild (von sicher analogischen Fällen wird abgesehen!):

a) aus idg. kurzem *-e: $\alpha$ ) eš- Nr. 1 , hueš- Nr. 3 (??), šeš- Nr. 4, -eš $\mathrm{Nr} .7-$ (šehur Nr. 29), ${ }^{\mathrm{r}}\left(\right.$ ehu Nr. 31) ${ }^{68}-$ genu Nr. 36, mene Nr. 37, -weni mit -meni und tteni Nr. $41-42-$ gemi Nr. 47, wemija- Nr. 48, mema- Nr. '49, memal Nr. 50 - milit Nr. 52, e-la Nr. 55 - kuer- Nr. 61, peruna- Nr. 62, piran Nr.63, werija- Nr. 64, werite- Nr. 65, -era- Nr. 66; $\beta$ ) keššer(a)- Nr. 12, kišša- Nr. 13, lešs̆ă, lišs̆ $\bar{a}-\mathrm{Nr} .14$, wešš- Nr. 15, peššija- Nr. 16, šešša- Nr. 17, -eššar Nr. 18, -ešša- Nr. 19, -ešš- Nr. 20 (vgl. Fn. 59 a), takkešš- Nr. 21 - penna- Nr. 43, zennaNr. 44 ;

b) aús idg. langem *-e-: eš- Nr. 2, šešarija- Nr. 5 - zena- Nr. $39-e l$ Nr. 53 , *el Nr. 54 - išmeri- Nr. 60; kein Beispiel mit Doppelkonsonanz! $!^{69}$

c) aus idg. Diphthong *ei- oder *oi-: weh- Nr. $30-$ gemanija- Nr. 47; kein Beispiel-mit Doppelkonsonanz!

d) aus idg. kurzem oder langem *-e-s weši-, wešija- Nr. 6 - eni, eniššan, apenišša Nr. 38; kein Beispiel mit Doppelkonsonanz!

e) aus idg. kurzem oder langem *-e-oder Diphthong *ei- oder *oi-: -enaNr. 40; kein Beispiel mit Doppelkonsonanz!

Auch ein Blinder könnte daraus den $\mathrm{Sch} l \mathrm{uss}$ ziehen, das $\mathrm{nach}$ historischem e, wenn es auf idg. langes *e oder Diph thong *ei oder *oi zurukgeht, also mindestens in einer vor. historisçhen Zeit lang war, alle in diesem Kapitel untersuchten Laute immer einfach geschrieben werden, nach solchem historischen e-, das a f idg. kurzes "e- zuruckgeht", da gegen die Einfachschreibung Regel ist, nur nach Präverbien pe und ze- und bei der Mehrzahl der s-Wörter D,oppelschreibung durchgefuhrt wird.

${ }^{68}$ Beide Wörter sind in Klammern gesetzt, weil ihr $-h$ sehr wahrscheinlich sekundär ist bzw. mit indogermanischen "Laryngalen " nichts zu tun hat; dazu noch pe-hute- Nr. 32, vgl. dazu noch oben im Text.und Fn. 62, weiter unten im Kapitel E.

69. Von sporadischen Ausnahmen abgesehen, vgl: Nr. 27 ! 
Der Parallelismus mit der Einfachschreibung der hethitischen Vertreter indogermanischer Mediae aspiratae nach historischem -e- ist jedenfalls sehr bemerkenswert, vgl, schon oben Kapitel C Schluss.

Da hier ein Vokal von so grosser Bedeutung für die Schreibung der nachstehenden Konsonanten ist, ist es m. E. ganz ausgeschlossen; dies mit einfacher orthographischer Mode zu erklären, die Unterschiede müssen im Lautsystem selbst gewurzelt haben, der Schreiber, wenn er aufmerksam genug war, muss sie vernehmen haben können. ${ }^{70},{ }^{70} \mathrm{a}$

Über die Ursachen des eben behandelten kombinatorischen Lautwandels wird erst unten in den Kapiteln $\mathbf{E}$ und $\mathrm{J}$ zu sprechen sein.

b) nach langem Vokal: dass es sich dabei um ursprachliche Quantität handeln muss, versteht sich von selbst, da ja man yon den hethitischen Vokalquantitäten herzlich wenig weiss, vgl. dazu zuletzt Kronasser $27 \mathrm{ff}$.; zu merken ist weiter, dass unten nur eine recht kleine Auswahl gegeben werden kann, denn nur recht Weniges ist hier völlig klar!.

Ich schicke voraus, dass in diesem Abschnitt nur die Laute $s, n, m, l, r$ in Betracht kommen können, denn mit inlautendem $h$ hat es eine besondere Bewandtnis, worüber weiter unten im Kapitel E gehandelt wird. ${ }^{71}$ Sonst kann noch das indogermanische lange $* \vec{e}$ - ausscheiden, denn es wurde schon im vorigen Abschnitt herangezogen." a Wir werden die einzelnen Fälle einfach in alphabetischer Ordnung vorführen, weil die Teilung nach dem zu untersuchenden Konsonant, wie sie oben zugrundegelegt wurde, hier infolge von Knappheit des Materials kaum lohnend ist.,

(1) $a r$ - whinkommen, gelangenu, z. B. in 3. Sg. $a r-i$, $a r-u$, zu ai. Pf. ära von or- isich bewegenu; vgl. auch gr. Pf. or $\overline{-o} r a$ von órnymai werrege mich";

(2) hulana- "Wolle», zu idg. * $(H) w i-n \bar{a}$ (mit langem sonantischem - - ) bzw. *(H)wlā-nā ds.; ${ }^{22}$

(3) $k \bar{a} r i$ in der Verbindung $k$. tija- "willfahren, nachgeben wohl eine Abstraktbildung auf $-r i i^{73}$ von idg. * $q \bar{a}$ - ngern haben, begehren",

70 Vgl. vor allem heš̀ gegentiber hašš- Nr. 8 und Pkt. c. Nr. 3 !!

70 a Vieles kommt noch unten zur sprache, vor allem die eigenartige seitenstellung von $-s-;$ man achte vor allem auf Ergebnisse der Konfrontierung der Fälle mit -ešš-aus idg. *-es- mit kurzem betontem *e mit denjenigen mit Doppelkonsonanz nach anderen kurzen ursprünglich betonten Vokalen am Ende des vorliegenden Kapitels.

${ }^{71}$ Es sei nur bemerkt, dass das hethitische $h / h h$ auf indogermanische Laryngale zurückgeht, die in der vorkonsonantischen Stellung mit vorausgehendem Vokal zu Längen zusammenfliessen mussten; Länge $+h / h h$ wäre demnach nur bei dehnstufigen Vokalen möglich.

71a Die übrigen langen Vokale der Ursprache werden hier ohne Rücksicht auf ihre Herkunft (Dehnstufe oder kurzer Vokal + Laryngal) herangezogen. Ich glaube nicht, dass gewisse Laryngale auch in vorkonsonantischer stellung im Hethitischen bewahrt blieben, eine Ausnahme vielleicht in der stellung vor $-s-$ (abèr historisch auch hier nur Doppelung von -s-) unten im Text am Ende des Pkt. I b).

${ }_{72}$ Es ist wohl zuzugeben, dass auch im Hethitischen lange sonantische Nasale bzw. Liquiden existierten, die dann ebenso wie $z$. B. im Lateinischen behandelt wurden; wer aber daran nicht glaubt, kann die zweitangeführte Urform benutzen. Zur heth. Wortgruppe zuletzt Friedrich, KZ. 77; 1961, 257. 
näher zu lat. cāa-ru-s »lieb», got. $h \bar{o}-r-s$ iEhebrecher, Hureru, lett. $k \tilde{a}-r-s$ wlìstern, begehrlich «; $;^{74}$

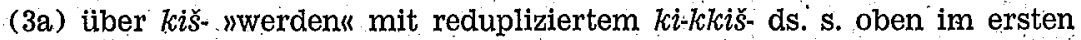
Teil der vorliegenden Untersuchung, Fn. 24 (Lingu, 5, 1964, S. 32); aus idg. aoristischem *qei-s- wkommen«;

(4) läman "Name«, zu idg. "nōmn ds.;

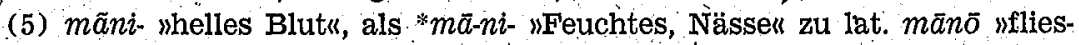
sen, strömenu usw.; ${ }^{75}$

(6) păs- ıschlucken, einen Schluck nehmen

(7) šamana- „Grundstein, Fundáment», mit dem idg. Suffix *-me/on- vòn heth. šăi- usw, nfestarücken, einprägen; (Kopfbedeckung) aufsetżen; (Zelt) aufschlagen; usw.u bzw. dessen idg. Grundlage, idg. etwa *sō-me/on ;"7 ,

(8) die primären Medialendungen auf ari (-ari, hhari, -ttari, -ntari u. a.) und auf -aru (-aru, -hharu, -ttaru,-ntaru) enthalten wohl zu einem gewissen Teil ursprachliches langes *a/o- vor $-r$-, denn sie müssen auch mit dem impersonalen * $\vec{a}-\dot{r}$ u. a. der keltischen Sprachen in Zusammenhang gebracht werden. ${ }^{78}$.

Die ebeñ genannten Fälle zeigen unzweideutig, das zw is c he der ursprachlichen langen Quantität des Vokals und der Einfachschreibung des unmittelbar folgenden Konsonanten èn kausales Verhältnis besteht. Dass es sich dabei wirklich um ursprachliche Längen (bzw, auch Diphthonge, die im vorhistorischen Hethitisch zu einfachen Längen zusammengezogen wurden) handelt und dass etwaige historische Quantitätsverhältnisse (die in keinem Zusammenhang mit ursprachlichen Quantitätsoppositionen zu stehen brauchen) von keinem Einfluss auf die Schreibung der unmittelbar folgenden Konsonanten zu sein brauchen, beweisen éinige wörter, die mit plene geschriebenen Vokalen vor doppelt geschriebenem $s$ usw. auftreten:

${ }_{73} \mathrm{Zu}$ solchen Bildungen z. B. Laroche, $R H A$. 13, fasc. $57,1955,82$; Neumann, KZ: 75, 1957, $88 \mathrm{ff}$.' Kronasser $225 \mathrm{ff}$; keiner nennt unser kāri.

${ }_{74}$ Nach Sturtevant, $\dot{C} G r^{2} 45$ f., 58 zu gr, kháris "Anmut, Gunstu und dessen Verwandten, idg. *g'her- ibegehren, gern habenu, was aber an der graphischen Behandlung des hethitischèn Wortes keine Stịtze findet; karija- ist wohl denominativ, nicht primär (zu gr. khaírō), wie schon die Bedeutung ausmacht, so dass man wohl käri- und nicht etwa *kära- bzw. sogar *kär-als Nominalstamm ansetzen muss.

${ }^{75}$ Álso = kymr. mawn "Torfi usw.

76. Z. B. Sturtevant, CGr. 51, 63. Freilich kommt auch Schreibung mit -šš- vor (Sturtevant 51 führt 3. Pl. paššanzi an, wozu noch luw. Inf. paššuna kommt), wo man entweder mit den Mitteln der graphischen Analogie auskommén kann oder aber diese Formen zu den Nr. 11-13 gehören? Doch kann diesmal idg. * $p \partial s->p a s ̌ s-$ angesetzt: werden; vgl., auch im Kapitel $\mathrm{E!}$

"Hierher auch arm. himn "Grundlagew; ganz dieselben Verknüpfungen auch bei Laroche, BSL. 58/1, 1963, 75 Fn. 2, 76 f.; doch ist arm. himn nur zur Hälfte mit heth. šamana- identisch, denn ein *e $>$ heth. a durch Assimilation (Laroche) ist unglaublich.

${ }^{78}$ Z, B. 'im mkymr. $-a w-r$, mbret. -eu-r (3. Sg. des Passivs), s. Pedersen, Kelt. Gr. II 392 usw. 
(9) ānninnijami- "Vetter» bzw. "Kusine» (oft a-a-an-ni-... geschrieben), wohl nichtindogermanisch; ${ }^{79}$

(10) ăšš- wübrig bleibeni (geschrieben $a-a \breve{s}-s ̌ s$ ), unbekannter Etymologie, aber doch wohl indogermanisch; 'šš- kánn natürlich auf verschiedene ältere Lautungen zurlickgefïhrt werden, z. B. "*ns-, *-ts-; auch das $\tilde{a}$ : braucht nicht immer nur einfaches $a$ - gewesen zu sein, es kann z. B. aus *aje/a-kontrahiert sein. Vgl. noch zu -šš- gleich unten Nr. 11-13!

So bilden derartige Fälle keine wirklichen Ausnahmen; wohl aber machen unserer Regel ernste Schwierigkeiten solche Wörter, die sichere indogermanische Etymologien besitzen und vermutlich auf Urformen mit idg. langen Vokalen zurückgehen, unserer Regel zum Trotz aber hinter der vermuteten ursprachlichen Länge doppelt geschriebenen Konsonant ( $s$ usw.) aufweisen:

(11) hišša- "Deichsel«, zu ai. $i s ̌ a \vec{a}^{\prime}$ ds., wohl damit ganz identisch, also aus idg. " $H \bar{\imath} s \bar{s}$;

(12) kuššan uLohn, Sold; Preis", zu ags. hyr wMiete, Lohn, Rente», nhd. Heuer aus urgerm. *hūaijō; ${ }^{80}$ vgl. aber mit einfachem -šn: kušata "Brautpreisu! vgl. dazu unten Pkt. III a 2;

(13) hašša- "HHerđú soll zu idg. *as- ıbrennen, glihhen" gehören; es wird gewöhnlich als eng verwandt mit lat. ăra, osk. aasaí win arau usw. angesehen; damit kommt es aber in Widerspruch mit unserer Regel. ${ }^{82}$

Die letzten drei Beispiele sind, unter Voraussetzung, dass ihre Grundformen wirklich mit langen Vokalen anzusetzen sind, sicherlich starke Beweise gegen unsere Behauptung; doch muss man zunächst hašša- ausschliessen, denn es ist durch nichts erwiesen, dass es mit ära völlig identisch ist: man kann auch von *Häso/ $\vec{a}$ - ausgehen, $\mathrm{d}$.h. von der kurzvokalischen Wurzelform oder, wenn sie ursprünglich langvokalisch war, von deren Reduktionsform mit *2; damit kommt unser Wort in die Nähe von d. Esse (*asjōn-). Die übrigen zwei Wörter könnten zur Not ebenfalls mit kurzvokalischen Grundformen erklärt werden; doch kann man hier einfach bei langen Vokalen blei-

79. So Kammenhuber, $K Z .77,1961,197$. Kronasser $220 \mathrm{f}$. scheint an luwische : Herkunft des ganzen Wortes zu denken.

so Cop, Die Sprache 3; 1956, $138 \mathrm{ff}$; vor mir, was ich ubersehen habe, Goetze, $L g .30,1954,403$. denkt.

ì Vgi. Pedersen, Hittitisch 27 und 164, der augenscheinlich an völlige Identität

82 Ein weiterer Fall mit (diesmal nur sporadischem) -šš hinter anzusetzendem langem Vokal ist pašš- $F n_{\text {. }}$ 76? Dazu könnte man noch das - freilich wohl nur luwische - Suffix -ašši/a- stellen (ausführlich dazu Kronasser 228 ff., zur Herkunft $233 \mathrm{ff}$, natürlich für churritischen Ursprung neben anderen, auch indogermanischen Quellen), wenn es mit lat. -ärius zu vergleichen wäre, was zuerst Pedersen, Lyk. u. Hitt. 34 für lyk. $-h i$ bzw. milyisch $-s i$ vermutete (weitere Lit. bei Kronasser 233) und Kammenhuber, $K Z$. 76, 1959, 24 in einer ganz tiberraschenden Richtung weiter ausfuhrt (auf beiden Gebieten nichtindogermanisch!?); doch ist der Ursprung dieses Suffixes zu dunkel, um darauf etwas zu bauen. Sogar das Tocharische kann mit seinem adjektivischen Suffix B -šše, A -ši herangezogen werden; ob mit Recht, ist eine hier nebensächliche Frage. Vgl. noch šakuwaššar

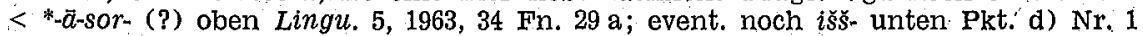
(s. Fn. 85). 
ben, denn hier kann es sich um eine auch sonst zu beobachtende Erscheinung

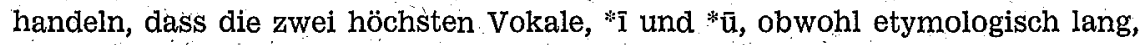
doch als kurz behandelt werden bzw. wirken. ${ }^{33}$ Und schliesslich kommt für alle drei Fälle noch die Tatsache in Betracht, dass sie áuf Wurzeln beruhen, wo ursprünglich vor ${ }^{*}$-s- ein Laryngal stand: hišša- von *HiHs-, kuššan usw. von * k'uHs-, hašša- von "HaHs-; die Gruppe "Hs kann aber im IndogermanischAnatolischen sehr lange erhalten geblieben sein, länger als in anderen indo- germanischen Sprachen, was endlich in der wirklichen Assimilation zum geminierten *-ss- seinen Ausdruck fand. Man braucht also auch hier keine wirklichen:Ausnahmen vor sich zu haben, so dass man getrost der oben vorgeschla;genen Regel Glauben schenken kann.

Zusammenfassend kann man zum Pkt. Ia-b sagen, dass sich der Vokal e- und die Längen wirklich fast gleichmässig in der Aussprache der unmittelbar folgenden Konsonanten $s, h, n, l, r$ a us wirken, nämlich darin, dass sich die silbengrenze vor den Konsonant verlegt bzw. der Konsonant in seinem implosiven Teil so stark reduziert wird, dass er für das Sprachgefühl dort bedeutungslos ist. Bedeutende Ausnahmen $\mathrm{macht}$ in beiden Fällen, hinter -e- und hinter langem Vokal, nur der Sibilant $s$; nur können wir für die Stellung nach der Länge auch andere annehmbare Erklärungen anführen.

Es ist wohl angebracht, hier auf die Schreibung der in diesem Kar pitel behandelten Konsonanten in der stellung nach den bisher nicht erwähnten Vokalen hinzuweisen; natürlich darf man hier nur einige sehr interessante Belege anführen, denn das ganze Material vorzulegen wäre in einer so rudimentären Arbeit, wie die vorliegende ist, kaum möglich. Wir berïhren nur folgende Punkte:

c) we $n \mathrm{n}$ in einem hethitischen Wort ein $\mathrm{zu}$ e rwartendes -e-, entstanden aus idg. kurzem *e, aus beliebigem Grunde (Assimilation u. a., Systemzwang, Ablautsneuerung) durch - $a$ - ersetzt wird, wird der

${ }^{33} \mathrm{~V}$.gl. sogar im Griechischen phô̂nix und kêryx trotz der langen Vokale $\bar{\imath}$ und $\bar{u}$ in den Suffixen. Im Hethitischen selbst könnten nöch andere Spuren solcher Wirkung der ursprünglich langen $* \vec{\imath}$ und $* \bar{u}$ aufgedeckt werden; ich nenne hier nur die Verhaltung des verbalen Präfixes $u$ - (hier)herı gegenüber der Schreibung des StammanTautes: dieser wird immer doppelt geschrieben, vgl.: $u$-mmijant- "jung" (Bedeutung unsicher!) zu $m \bar{a} i-/ m i j a$ - swachsen, gedeihen, reifenu, $u-n n a-$ whertreiben, herschicken zu nāi-/neja- )lenken, leiten usw.«, $u$-ššija- )(Vorhang) aufziehen; (Verborgenes) enthüllen( zu pe-ššija- )werfen, stossen, verwerfen usw.u (doch nicht $u$-das(her) bringen«, da im Anlaut der Verbalwurzel idg. * $d-\cdot$ steht, oben Kapitel A Nir. 10). Seit der Entdeckung der luwischen Entsprechung zu heth. ui-; uwaskommenu, aw-i- (Laroche, RHA. 16, fasc. 63, 1958, 99 ff.), wird man das hethitische $u$ - ebenfalls auf eine diphthongische Urform zuruickführen müssen, idg. *au-; Kronassers Konstruktionen (S. 71) können heth. $u i-, u w a$ - nicht vom luwischen $a w-i$ trennen und das Präfix als aus "au- entstanden nicht widerlegen, obwohl gewisse lautgeschichtliche Schwierigkeiten auch (besser gerade) bei *au-bleiben. - Wenn aber $u$ - aus *au- entstand, muss es notwendigerweise über die Stufe ${ }^{*} \bar{u}$ zür historischen Form, die die Wirkung eines kurzen betonten Vokals aufweist, gegangen sein. Vgl. noch 'im Kap. E, Pkt. I! 
unmittelbar folgende Konsonant $(s, h, n, m, l, r)$ doppelt geschrieben:

(1) ammuk usw. mmir, mich« gehört bekanntlich zu gr. emé usw.; diese Formen enthalten aber einen stamm *me, der vorne mit einem deiktischien Element * $e$ - verstärkt ist; selbstverständlich können aber solche deiktische Partikeln sehr schwer reduziert werden, m. a. W., heth. ammuk usw. beruht wohl auf Assimilation aus "emu-!

(2) aššu- "gutu mit allen Ableitungen (aššul "Heil, Wohlergehenu ašš

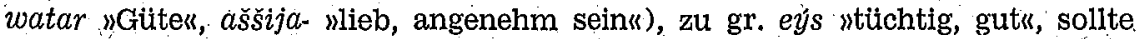
auch anlautendes $e$ - haben; der Ersatz desselben, einerlei ob durch Assimilation (in den Kasus obliqui usw.) oder weil darin idg. Reduktionsstuffe steckt, bewirkt augenscheinlich die Doppelschreibung von -s-!

(3) sehr interessant ist es weiter, dass man in einigen Verbalparadigmen mit wohl altererbtem Ablaut einem Wechsel zwischen einfach geschriebenem Konsonant nach e-Vokal und gedoppeltem nach anderen Vokalen begegnet; so vor allem in dem etymölogisch noch dunklen hašš-, heš- »öffnen«: Präs. 3. Pl. hešanzi, Prät. 3. Pl. hešer, hešir, Part. hešant-, Verbalsubst. hešuwar, Iter. hešik- gegenüber Präs. 3. P1. haššanzi, Prät. 3. Sg. haššit, Part. haššant-; wirkliche Ausnahmen bilden nur Präs. 3. Sg. hāši und Imper. 3. Sg. hāšu, woruber.unten im Kapitel $\mathbf{E}$ !

(4) eine spezielle Stellung nimmt heth. $h$ ein, da es intervokalisch fast immer doppelt geschrieben wird, auch kaum ein einziger Fall mit ursprachlicher Länge - ausser weh- oben I a 2, Nr. 30 - vor einstigem Laryngal angeführt werden kann; näher über diese Fragen im Kapitel E!

(5) über sonstige Wechselfälle zwischen doppeltem und einfachem Konsonant in demselben Verbalparadigma weŕden wir unten im Kapitel $\mathrm{E}$ handein.

d) um dem oben unter a) und b) erschlossenen Grundsatz von der-Abhängigkeit der Einfachschreibung der in Frage stehenden Konsonanten von der Farbe und Länge der vorhergehenden Vokale volle Beweịskraft zu verleihen sol1te man hier noch die Schreibart dieser Konsonanten nach den übriggebliebenen Vokalen, d. h. nach den ursprachlichen kurzen Vokalen " $a, *{ }^{*} i$ und * $u$ (und $* \partial$, das aber bekanntlich zuerst zu urănatol. kurzem *a geworden ist, sowie sonstigen reduzierten Vokalen, die auch mit vollen ursprachlichen Kürzen zusammenfielen), genau untersuchen: stellte sich dabei heraus, dass in dieser Stellung unsere Konsonanten nur doppelt geschrieben werden, dann hätten wir im oben erwähnten Grundsatz eine unerschütterliche Wahrheit vór uns. Leider steht es mit der Schreibung unserer sechs Konsonanten in der erwähnten Stellung nicht so, richtiger, nicht so einfach; denn hier muss man doch wohl viele andere phonetische Elemente - Akzentstellung, vor allem $^{84}$ - dafür schuldig machen, dass das eben geformte Gesetz nicht einfach in allen derartigen Fällen hervortritt. Auch würde es uns zu weit führen, wenn

84. Dazu mehr im Pkt. III a. 
hier alle in Betracht kommende Fä́lle erörtert werden sollten; denn die genannten Vokale und Konsonanten sind so häufig, dass etwa die Hälfte des bekannten hethitischen Wortschatzes herangezogen werden muisste. So können wir genauere Untersuchungen über diese Fragen der Zukunft überlassen und hier nur die ausgiebigsten Beispiele vorführen.

1. nach indogermanischen kurzen Vokalen - ausgenommen ist *e - werden unsere sechs Konsonánten $u$. a. in folgenden Fällen doppelt geschrieben:

a) mit -šš-:

(1) išš- als schwacher Stamm zu Nom.-Akk. Sg. aiš mMundu, wohl mit idg. kurzem $* i-;$;5

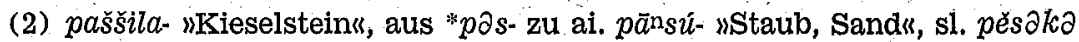
"Sandi, Pisani, JKF. 2, 1952/53, 217;

(3) dašš- ')stark, festu, aus *dnsu- zu gr. dasýs wdicht»;

(4) das Femininsuffix -ššara- in *haššu-ššara- "KKönigin! (Fem. zu haššu"Königu), išha-ššara "Herrinu (Fem. zu išha- "Herru), šuppi-ššara- bzw.

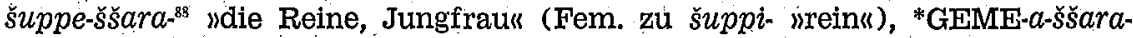
"Dienerin, Sklavinı im -Verbum GEME-aššareš- nunfrei werdenu, zu idg. Wortelement *-sor- in *swe-sor- "s Schwesterw; ${ }^{89}$.

(5) das Genitivsuffix - $s$ wird doppelt geschrieben in $t \bar{a} n$ pedašš-ahh- wzweiten Ranges machen, zum Lehensmann machen", Ableitung von dän pedaš wzweiten Ranges";

85-Vgl. ähnliche Ablautverhältnisse im Paradigma des $u$-Wortes *ous-, * $\partial u s-$, " $u s-$ "Ohr«; wer aber bei *is- als Reduktionsstufe von aiš beharrt, kann das doppelte -šš- von išš durch die Fälle, die oben im Pkt. I b Nr. 11-13 vorgestellt wurden, begreiflich machen.

${ }^{8}$ Das Wort ist sicher in dem Pflanzennamen hašuššara- enthalten, vgl. Luaroche, $R H A$. 7, fasc. 46, 1946/47, 104 ( $=$ Recherchés sur les noms des dieux hitt.). Dadurch ist auch das doppelte -šš in diesem Worte gesichert.

${ }_{87}$ Die meist plene geschriebenen Vokale der letzten Silbe von išha- wFIérru bezeugen doch wohl keine echte Länge; vgl. Pedersen, Hittitisch 34, so dass auch unser Fall kurzes - $a$ - vor -šsara- gehabt haben muss.

${ }^{88}$ Das -e-von šuppe-ššara- ist natürlich kein altes -e-im Sinne von Pkt. I dieses Kapitels; es handelt sich wohl um eine ungenaue Schreibung oder eventúelie lautgesetzliche Entwicklung eines älteren -ija-.

${ }^{89}$ Ausführliche Literatur über die Herkunftsfrage dieses Suffixes bei Kronasser $109 \mathrm{ff}$., der natürlich an kappadokische, d. h. jedenfalls nichtindogermanische Herkunft glaubt. Jedoch hat weder er selbst noch einer seiner Vorgänger irgendetwas Entscheidendes beibringen können, auch ein idg. "-sor- wFrau॥ bzw. Femininformans (im weitesten Sinne des Wortes Formans) kann durch die bisher vorgebrachten Deutungsalternativen der in Betracht kommenden Wörter keineswegs aus der Welt geschaffen werden, die Deutung des lat. Wortes uxor, die von Pisani stammt; ist, sehr mild gesagt, abwegig. Doch ist hier aus Raummangel nicht möglich, auf diese Frage näher einzugehen. Jedenfalls ist es rätlich, auch das Hethitische nach dem bekannten. Grundsatz nden sprachschatz einer Sprache zunächst aus dieser Sprache selbst zu deutenw zu beurteilen, $d . h$. seine Sprachelemente, wo kein sachlicher Grund dagegen spricht, in erster Linie auf das Indogermanische zurickzufithren; in unserem Fall - das muss besonders scharf betont werden - wurde nämlich bisher kein zwingender Beweis sachlicher Natur zugunsten der nichtindogermanischen Herkunft beigebracht. 
(6) das Verbalsuffix -šš- aus idg. aoristischem *-s- in ištama-ššs- "höreni, ${ }^{90}$ dama-ššs- neben dame-ššs «drücken, drängen $\|^{11}$ u. a.;

(7) hierher die Pronominaladverbia ki-ššan uin dieser Weise, soแ, eni-šsan iso; in der erwähnten Weise", apeni-ššan uso (wie erwähnt)», mit anderer Beđeutungsschattierung $k u$-ššan "wann" mit kuššanka virgenđwann, jemals", ausnahmsweise mit einfachem -šs anni-š̆an ufrüher, einstu; ;1 auszugehen ist von $k i$-ššan, wo an idg. * *k' $i$ ein $s-S u f f i x$ angetreten ist, vgl. lat. ci-s vdiesseitsu, und wohl auch von $k u$-ššan, wo ebenfalls ein s-Suffix an ein idg. *qw $u$ trat;

(8) ein Lehnwort ist aššuššanni- «Stallmeister o. dgl.. aus ai. aśva- „Pferd" + ein mit Sibilant anlautendes zweites Kompositionsglied; ${ }^{92}$

B) mit -hh-:

vgl. oben unter c) Nr. 4, weiter im Kapitel $\mathbf{E}$;

r) mit -nn:

(9) "wanna- imangelnd; beraubt, ermangelnd, vereinsamt; verwaistu in wannummija- walleinstehend; elternlos, verwaist; kinderlosu und in den $\mathrm{Zu}$ sammensetzungen anna-wanna " stiefmutter" und (nur luwisch!) tata-wanni"Stiefvater», zu idg. *wano- bzw. *wono- "mangelnd, leeru bei Pokorny, Idg. $E W .345 ;{ }^{93}$

(10) das Demonstrativpronomen *anna- ijeneru in den Weiterbildungen und Ableitungen: annaz(a) weinst, früheri, anni- njener", annal(l)a/i- ifrüherer, uralt«, annišan "früher, einstı u. a.., ${ }^{93}$ zu idg. *ono- njener»;

${ }^{90}$ M. E. muss man hier ein uranatol. *stamn-s- ansetzen, das entweder aus dem n-Stamm ištaman- „Ohru direkt abgeleitet wurde oder ursprünglich wirklich nur aorịstich war und zu einem Präsens *staman-je/a- (mit -an- aus reduziertem *-en-) in einer Zeit trat, als das Hethitische noch den s-Aorist kannte.

91 Die Verbindung mit gr. edámassa sbändigte» usw. kann zutreffen, doch muss man im Hethitischen jedenfalls mehrere Analogievorgänge voraussetzen, da auch -ešs- vorkommt, das zu idg. *demā- mzähmen nicht stimmt.

${ }^{92}$ Literatur bei Kronasser $143 \mathrm{f}$. Das Wort kann und wird ins Hethitische in der schon zusammengezogenen Form *asusani- gekommen und $-w a->-u-$ schon churritisch vorgenommen worden sein.

${ }^{93}$ Woher Kammenhuber, $K Z .77,1961,197$ ihre feste Utberzeugung schöpft, dass annawanna-samt luw. annawanni- und tatawanni- fremd sind, ist tatsäschlich schwer zu entdecken; auf jeden Fall vermisst man bei ihr das wichtige wannummija-, das seinem Bedeutungsinhalt nach gewiss nicht bzw. ursprünglich nicht zu den Verwandtschaftsbezeichnungen gehörte, dàs jedoch von -wanna/i- kaum getrennt werden kann; zur Entwicklung des Begriffes "Stief-vater/-mutteru in hethitisch-luwischen Ausdriucken vgl. eben d. Stief- bei Kluge-Mitzka, DEW. ${ }^{18}$ 749. Zum Kompositionstypus vgl. gr. hippo-pótamos. -wanna/i- muss also aus vberaubtu eben zu wverwaist, Waise vorgeschritten sein. - Lautlich $\mathrm{zu}$ schwierig ist die ebenfalls indogermanistische Deutung von Neumann, KZ. 75, 1957, 90; sie lässt übrigens -wanna/i- ausser Acht.

Dabei bleibt freilich eine formgeschichtliche Schwierigkeit übrig: das Suffix -ummija- von wannummija- ist auf jeden Fall seltsam; schon die $u$-Vokalisierung gegenuiber dem 2. Kompositionsglied -wanna- mit auslautendem - $a$ - ist mit bekannten hethitischen Wortbildungsmitteln schwer zu erklären; ein Verbalstamm *wannanach der Klasse II 2 c (Friedrich, Heth. El. $\mathrm{I}^{2} \S 174$ ) als Brücke dazu wäre allerdings möglich: ein Verbalsubst. *wannummar sVereinsamung o. dgl.» kann, weil hier die Analyse ein Wortstück *wannumm- herauslösen musste, sehr wohl Grundlage für eine Weiterbildung mit dem Zugehörigkeitssuffix -ja- (idg. *-jo-) gebildet haben. 


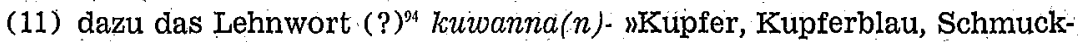
stein«, zu gr. kýanos "Lasur-, Blaustein usw.";

(12) vgl, noch das Verbalsuffix -nna- z. B. in šunna sfüllen«; aus idg. * su-n-āa- zur zweisilbigen Basis in šuwa - ufüllenı usw.;"

o) mit -mm-:

(13) lammar "Stunde«, aus "nomr zu lat. numero "sofort", Neumann bei Friedrich, $H W$. Erg. 1, s. 12 ;

(14) imma wvielmehr, sogar usw.u, zu lat. immō inein, vielmehru;";

(15) dazu das Suffix -mmar z. B. in hila-mmar "Torbau», harna-mmar „„Hèfe; Gärung, Aufruhr, Unruhe» usw., zu idg. *mr;

ह) mit - $l l$-:

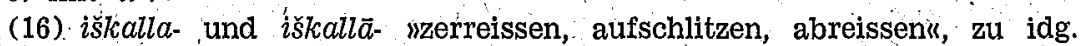
"sqel- ischneiden";

(17) kallešš- irufenı, zu gr. kaléō "rufe usw.u;

(18) málla imahlen«, zu lat. molö, lit. malu, got. malan ds.; ${ }^{97}$ dazu die Reduplikationsbildung memal- iGruitzen, wo jedoch - $l l$ - nur selten vorkommt, einfaches $-l$ - aber nach Plst. III a gut erklärt werden kann. ,

(19) das Suffix der Nomina agentis , (t)talla- kann auf idg. *tel- oder eventuell auf *-tol- zurückgeführt werden; doch könnte man auch mit idg. -tel-auskommén und - $a$ - vor - $l l$ - mit Assimilation erklären, das - $l l$ - dann nach Pkt. c) oben begrunden:

६) mit $-r r$ :



(21) šarra- nabbrechen, wegreissen, trennen usw "l mit der Ablèitung šarra"Teilu, als *sworo- zu d. Schwert usw., Cop, SlR. Lingu. 9, 1956, 28 ff.;

${ }^{93} \mathrm{a}$ Falls heth. $a-n i$-ši-wa-at wheutew bedeutet, muss das Vorderglied $a-n i$ idieser bedeutet haben, d. h. auf keinen Fall mit unserem anni- sjenerw zusammenzuhalten sein; es handelte sich dann um ein weiteres Pronomen auf - $i$ (vgl. bei Friedrich; Heth. El. $\mathrm{I}^{2} \S \S 117$ und $118 \mathrm{eni}$, uni, aši), das in Hinblick auf Pedersens, Hittitisch 60 fuir $a s ̌-i$ und $u n-i$ gegebene Analyse als Akk. Sg. an + deiktische Partikel *i.(eigentlich lang) erklärt werden könnte; vgl. auch weiter unten im Text, Pkt. III a. Nr. 9. Zu anišiwat zuletzt Kammenhuber, KZ. 77, 1961, 195 Fn. 1.

Weitere wahrscheinliche Ableitungen unten im Text, Pkt. III b Nr. 7.

"4 Zuletzt uber die whethitischei Wortsippe'Kronasser 196. Das griechische Wort bezeugt. wohl die ursprünglichen Quantitätsverhältnisse, mehr aber nicht.

${ }_{95}$ Das danebenstehende šunïja- (auch šü-) kann zu Pkt. III b gehören, $d$. sein einfaches $-n-$ durch Einwirkung eines unmittelbar folgenden $-j$ - zustandegebracht worden. sein; oder aber geht es auf ein Part. auf -no- "sü-no- "gefullti mit regelrechtem * $-\bar{u}$ - als Schwachstufe $\mathrm{zu}^{*}$-ew $\overline{\bar{a}}$-? Sein einfaches $-n$ - ist in beiden Fällen in Ordnung!

${ }^{6} \mathrm{Da}$ auch eine gute ttymologie für lat. $i m m o ̄$ aussteht (s. Walde-Hofmann, $L E W .^{3}$ I $682 \mathrm{f}$. ), ist es möglich in heth. lat. $-m m$ - auch Assimilationsprodukt zu sehen; dann gehört unser Beispiel in das Kapitel E. Am besten (vorläufig) über das heth. Wort (ohne lat. $i m m \overline{)}$ ) Neumann, MSS. 16, 1964, 48. Dann sicher mit urspr. kurzem $i$-, doch - $m m$ - noch-immer zweideutig!

${ }_{97}$ malla- samt angefuhrten Verwandten (nur das lateinische Beispiel ist mehr: deutig) gehört zu einem uridg. Verbaltypus mit -o- in der Wurzel und ebensolchem Stammauslaut, vgl. vorläufig čop, SlR. Lingu. 9, 1956, 28 f.; vgl. noch im Text Nr. 16, 20 und 21. Vgl. noch S, 33 Pkt. 3 a) Nr. $\zeta$ ("kalla-). 
(22). die Endung -arr-i im Nom.-Akk. Pl. der heteroklitischen Neutra, z. B. zankilatarri "Bussen", kann ein idg. *-or $i$ mit kurzem - 0 - sein gegenüber $-\bar{a} r$ im gleichen Kasus anderer Heteroklita, z. B. uddār "Worte», aus idg. *ōr (oder aber aus *-or-2?) ${ }^{98,},{ }^{88} \mathrm{a}$

Es gibt recht viele Wörter und Formen, die diesem Gesetz widerstreiten; inwieweit es sich dabei um indogermanische Grundformen mit nachweislich kurzem Vokal vor dem in Frage stehenden Konsonant handelt, können wir sie noch nach. Pkt. II (Stellung vor $-w$-) oder nach Pkt. III a (der vorausgehende Vokal ursprünglich unbetont) bzw. nach Plkt. III b (Śtellung vor $-j$-) beleuchten; in anderen Fällen wieder können statt der vermeintlichen kurzen Vokale lange angesetzt werden; dann hätten wir mit dem Gesetz von Pkt. $b$ oben zu tun; so beurteile ich z. B.: das Suffix der Nomina agentis -ttara, wo ein nach dem Nom. Sg. umgeformtes *tōr- gesucht werden kann, vgl, lat. -tōr-; das Femininsuffix -ššara- (vgl. oben Nr. 4), das ebenso nach dem Nom. Sg. zunächst zu *sōr-geworden sein kann, vgl. lat. sorōr-, uxōr-!

2. wenn oben nur Fälle mit dem fraglichen Konsonant in intervokalischer Stellung herangezogen wurden, können wir hier noch einige Beispiele von Doppelschreibung unserer sechs Konsonanten in anderen Lagen, d. h. zwischen Vokal und Konsonant, zwischen Konsonant und Vokal und zwischen zwei Konsonanten, untersuchen; geordnet nach der Lage:

a) zwischen Vokal und Konsonant:

(23) išna- neben išsana- iTeig», mit idg, *i-, zur Etymologie vorläufig Čop, $\check{Z} A$. 6, 1956, 42, 49 (zu idg. *jes- wwallen, schäumen॥);

(24) ein * *šna- bzw: *uššana- wKaufpreis; Handelu wird vorausgesetzt durch ušnija- neben uššanija- ufeilbiețen, verkaufen«, zu ịdg. *wesno-, *wosno"Kaufpreis";

${ }^{98}$ Dazu Brugmann, Grdr. II 2, 235 ff. Wenn der Alzzent auf *-or- stand, konnte er daselbst bleiben, nachdem *-a geschwunden war, und hielt sich dort bis in die hịstorische Zeit hinein; vgl. Fn. 118!

98a In diese Gruppe gehören auch die primären Verba und Nomina mit Ređuplikation; vgl.:

1, hu-hharti- (auch huwa-hharti- geschrieben) wKehle« bzw. "Luftröhre«, wegen huwa-hhuwart-alla- "Halsketter wohl hu-hhurti- zu lesen; vgl. Pkt. II Nr. 15; Etymologie unbekannt;

2. mi-mma- isich weigern, etw. verweigern, zurückweisenk, wohl indogermanisch, jedoch nicht zu gr. mimnō vbleiber trotz Sturtevant; $C G r^{2} 43$ usw., sondern wohl zu einer einsilbigen schweren Basis auf *-ä; mehr anderswo;

3. na-nna- streiben«, zu nāi-/neja- »lenken, leiten usw,k;

4. A. ṠÀ ši-ššra- "Marsch, feuchter Boden《 mit ši-ššurija- (ši-ššiurija) »bewässern«, wenn indogèrmanisch, sehr einfach als reduplizierte Bildung zu idg. "sü-ro- bzw. *sou-ro- sfeucht - sauer, salzig, bitteri, vgl. vor allem sl. syra "feucht«, anord. saurr nSchmutzu.

Nicht als Gegeninstanz können andere reduplizierte Bildungen gebraucht wèden, wo der Wurzelanlaut einfach geschrieben wird, vgl. la-lukki- whell zu lukk"hell werdenu, li-lakk- »biegen, beugenw zu lag- mneigen, beugen usw.«, denn sie können als junge Bildungen (in Gegensatz zur Mehrzahl der die Doppelung aufweisenden haben sie alle das Grundwort neben sich!) nicht mehr unter unser Gesetz gefallen sein, Vgl, noch im Kapitel E! 
(25) in den Kausativa der Verbalstämme auf : (̌s) $\breve{s}$ - kommen ebenfalls solche Varianiten vor: šašnu- neben šaššanu- mzum Schlafen veranlassen, bettenı, zu šeš- ıruhen, schlafenı oben Plst. I a Nr. 4; der Fall gehört eigentlich zum Pkt. c, jedenfalls enthält das Kausativum ein entweder auf Ablaut oder analogischer Umförmung fússendes $a$, das dem -s- den Weg zur Doppelschreibung eröffnete; ganz ähnlich steht es mit ašnu- neben aššanu- wherrichten, ordnen, fügen usw.", einerlei ob es zu eš- iseinu oder zu eš- isitzen« gehört;

(26) das Iterativsuffix-sk- wird in besonders gunstigen Fällen mit doppeltem -šš- geschrieben: hašši - zu hanna- ientscheiden, richten« und zu einem

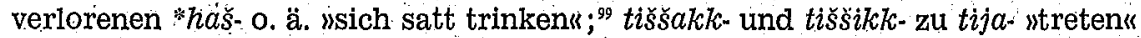
und zu däi- issetzen, legen, stellen"; in allen diesen Fällen handelt es sich um alte Schwundstufen der genannten .Wurzeln bzw. bei ti- zu däi- wohl um Analogiebildung nach $t i$-zù $t i j a$;

(27) andere Fälle, darunter ziemlich zahlreiche mit der Konsonantengruppe $h+$ Konsonant, sind etymologisch unklar, so dass eine sichere Schlussfolgerung auf dieser Grundlage unmöglich ist; nur ein Vérbalstamm wie pahš- neben pahhaš- ischützen, verwahren « kann herangezogen werden, da ein idg. "paH zugrundeliegt und keine Analogieschreibung ${ }^{99}$ möglich war;

(ß) zwischen Konsonant und Vokal: hier muss man besonders darauf achten, dass der Schreiber in fast allen derartigen Fällen einerseits mehrere Möglichkeiten zur Bezeichnung der Konsonantengruppe hatte, anderseits aber ihm sehr wohl bekannt war, dass andere zu demselben Flexionssystem gehörige Formen infolge von verschiedener Lautstruktur mit anderen schriftlichen Mitteln bezeichnet werden mussten; so konnte er aus anderen Formen auch in diejenigen mit der hier behandelten Lautstruktur gewisse Schreibungen übertragen; vgl, zu Derartigem Friedrich, Heth. El. $\mathrm{I}^{2} \& 23$; Kronasser $15 \mathrm{f}$; dennoch kann man folgende Fälle ins Feld führen:

(28) pailzasha- neben palzaha- und palzahha- "Sockel", sicher indogermanisch, und zwar aus *plt( $\partial$ )- "breit und flach" + Suffix -šha demnach wohl paltshha- gesprochen; ${ }^{100}$

(29) tekkušša- mzeigen" gehört ebenfalls hieher, wenn die Etymologie von Goetze, die auf idg. "deqws führt, s. oben Kapitel B II a 3 Nr. 3 b, richtig ist, was gewiss der Fall ist;

(30) auch walhi neben walahhi-, Name eines kultischen Getränks, kann als Beweis für unsere Annahme angeführt werden, da es kaum graphisch von walahh- uschlagen" beeinflusst sein kann; doch ist der Name wohl fremd,

9 Das Grundverbum erhalten im pal. haš- isich satt trinkenı, vgl. Kammenhuber, $R H A$. 17 , fàsc. $64,1959,23,47,49,74 \mathrm{f}$.

sa Ein *pa-ha-aš-, das zu einem "pa-ah-aš- für die kombinierte Schreibung


eigentlich eine Aussprache * phas- vortäuschèn!).

${ }^{100}$ Zur Etymologie, die oben angegeben wurde, vgl. schon Haas an mehreren Stellen (bei Kronasser 58); doch ist seine Analyse, für die sich im allgemeinen auch Kr. a. a. O. entscheidet, kaum richtig, Laroche's pa-a-al-za seinem Zugeständnis nach unbrauchbar, $t / 2$ schwierig. Mehr anderswo. 
vielleicht mit dem churritischen Suffix - $h i$ - gebildet, vgl. Kronasser 209, wobei jedoch ins Auge fällt, dass dieses nur äusserst selten mit doppeltem - $h h$ geschrieben wird; Lautsubstitution, $\mathrm{d} . \mathrm{h}$. anstatt churr. $h$ - hethitisch gesprochenes $-h h$ ?

y) zwischen zwei Konsonanten: hier ist es wirklich fast unmöglich, analogisch beeinflusste Schreibungen von den durch die Lautform selbst geför. derten zu scheiden. Doch fragt man sich mit vollem Recht, ob eine Schreibung wie Part. paraššanant- zu paršnă- "sich niederhocken» wirklich einfach als Verquickung von par-aš-na- und par-ša-na- zu erklären ist; denn man sollte in solchen Fällen dann doch wohl auch Schreibungen wie par-ša-aš-na- erwarten, was nur unter besonderen lautlichen Bedingungen vorzukommen scheint, $\mathbf{s}$. hier unten und im Kapitel I.

Die unter dem Pkt. 2 Nr. 23 ff. gegebenen Erörterungen gelten nicht nur für die in diesem Kapitel untersuchten sechs Konsonanten in der Stellung nach kurzem Vokal, sondern auch für dieselben in n'a chk ons onanti. scher stellung, wo von einem Einfluss des Vokals auf ihre Graphie keine Rede sein kann; daraus ist wohl der Schluss zu ziehen, dass die doppelt geschriebenen Konsonanten in allen solchen Stellungen nicht nur sprachwirklich sind, sondern ihre geminierte Realisierung auch lautgesetzlich ist; weiter folgt daraus, dass die einfache Aussprache und danach einfache Graphie dieser Konsonanten nach langem Vokal und nach jedem e-Laut eben durch diesen Umstand bedingt ist und somit auf einen kombinatorischen Lautwandél weist, der auf vielen Sprachgebieten nachweisbar ist: die Beeinflussung der Konsonanten durch die Quantität der vorhergehenden Vokale, die weiter in der Verschiebung der Silbengrenze ihren klarsten Ausdruck findet. Die hethitische Orthographie weist also mit ihren Doppelschreibungen nach kurzem Vokal und nach Konsonant, dass unsere sechs Konsonanten, $s, h, n, m, l, r$ in diesen Stellungen geminiert bzw, auf zwei Silben verteilt gesprochen wurden; dann ist es auch begreiflich, dass kein "par-ša-aš-na- (s. oben) vorkommt, denn durch diese Schreibung würde die tatsächliche Aussprache dieses und ähnlicher Wörter mit der Silbengrenze im Innern des betr. Konsonanten (etwa pars:sna-) kaum zum Vorschein kommen; wohl aber kommt eine die Kombination der Zeichen Konsonant + Vokal und. Vokal + Konsonant zur Bezeichnung eines einzigen. Konsonanten verwendende Orthographie dort ziemlich oft vor, wo die Silbengrenze ausserhalb des só zu bezeichnenden Konsonanten liegt, z. B. in unserem Beispiel Nr. 28: hier muss man also die Silbengrenze in - $h$ h- suchen, also paltsh:ha- Die wahre Aussprache der unter dem Pkt. d) angeführten wörter ist also z. B. das:su-Nr. 3, kis : san Nr. 7, an: na- Nr. 10, sun:na- Nr. 12, lam:mar.Nr. 13, mal:la- Nr. 18; ar:ra- Nr. 20, is:sna- Nr. 23, us:snija- Nr. 24, sas:snu- Nr. 25, has:sk- und tis:sk- Nr. 26, pah:hs- Nr. 27, tekkws:sa- Nr. 29.101

101 Man berúcksichtigte hier nur die in Frage steheñden Konsonanten bzw. Konsonantengruppen, über genaue Aussprache z.' B. von $d$ - in daššu- mag man streiten: Weiteres uber die Silbentrennung im Hethitischen im Kapitel E, auch uber verwandte Erscheinungen in anderen indogermanischen Sprachen Anatoliens. 
Vieles kommt weiter im Kapitel $E$ zur Sprache; $h$ i e r $d \ddot{u}$ rfen wir unsere Unterșuchung mit der Feststellung 'schliessen, das a u ch bei. $s, h, n, m, l$ und $r$ die Farbe und die $Q$ uantität des vor. hergehenden Vokals auf ihre tatsächliche Aussprache, durch diese aber auch auf ihre Schreibung von ent. scheidendem Einfluss waren.

II. Die Laute $s, h, n, m, l, r$ vor dem Halb vokal -w-:

a) die intervokalische Gruppe $-s w$ :

1. mit einfach geschriebenem - -5 :

(1) hišwă- noffen stehen«, zu hašš- yöffnen«, vielleicht über einen $u$-Stamm, vgl. hatku- "seng" von hatk- "schliessen"; ; $^{102}$

(2) huišwā- ulebenı mit huišwant-, hušwañt- 川lebend" und huišwatar "Leben", über das Adjektivum huišu-, huešu- "lebendig" zu hueš- ulebenu, doch ist hier das einfache -š- auch unter dem Einfluss des vorhergehenden - $e$ Vokals, s. Pkt. I a 1 Nr. 3 und. Fn. 58 a;

(3) dašuwant- iblind" mit dašuwahh- "blind machen, blenden", angesichts des Verhaltens der adjektivischen $u$-Stämme in den Ableitungen auf $-a h h^{-103}$ wohl von keinem $u$-Stamm, sondern von einem idg. "wo-Stamm; bisherige Etymologien kaum annehmbar, ${ }^{103}$ ich schlage vor den Anschluss an germanische Wörter wie norw. dial. tase uschwächlicher Mensch", tasa sentkräftet werden" u, a. bei Pokorny, $I d g . E W .178$, mit Spezialanwendung eines idg. *das-wo- "kraftlos, mit körperlichen Fehler behaftet» (auch andere Ausgangspunkte könnten vermutet. werden) auf nur ein Gebrechen im Hethitișchen;

(4) tapašuwant- "fieberschwangeri (zu lesen tapaswant-), mit bekanntem Suffix von tapašša- ifieber, Hitzen, ist leider fremd, wie der Glossenkeil vor dem Worte beweist, könnite dennoch auf eine spezielle hethitische Sprechgewohnheit bei der Utbernahme der Bildung hindeuten; ${ }^{104}$

2. mit doppelt geschriebenem -šš-:

(5) aššu- "Gut, Besitz, Habe, Heil, Wohlergehen usw.u wird in den Kasus obliqui ebenfalls mit -šš- geschrieben: Abl, aššuwaz, Instr. aššuit, Nom.Akk. Pl. aššuwa usw., zu sprechen asswats usw.; natürlich unter dem Einfluss des Nom.-Akk. Sg. sowie der adjektivischen Formen!

(6) haššuwä- "alls König herrschen« ist ebenfalls unter dem Einfluss des Nomens haššu- ॥Königu gestanden;

(7) eine ganz vereinzelte und deswegen schwer erklärbare Schreibung ist $h u-u-i s ̌-s ̌ u-u-i z-z i$ wer lebtu Huqq. III 31 zu Nr. 2; jedenfalls Entgleisung; ${ }^{105}$

${ }^{102} \operatorname{Ein}_{1}{ }^{*} h i s ̌$ - "patens erschliesst auch Laroche', $R H A .18$; fasc. $67,1960,84$.

103. Vgl. idalawahh- "Böses tun, schädigen« zu idalu- »böse, schlecht«!

${ }^{10}$ a Zur Verknulpfung mit ai. támas-vant- iffinster巛 usw. zuletzt Mayrhofer, Kzgef. EW. d. Altind. I 478 mit Lit.

${ }^{104}$ Zuletzt ibber die Herkunft dieses. Wortpaares Kronasser 144 und 267 (indisch); uber eine andere Entwicklung im indischen Lehnwort vgl. aššššanni- Pkt. I d Nr. 8 mit Fn. 92!

105 Dafür spricht wohl auch $-u$ - statt des zu érwartenden $-w a$ vor der Endung. Sonst wird die ganze Wortgruppe mit. einfachem -š- geschrieben! Doch vgl. Fn. 109. 
(8) das Suffix -want- tritt bei den pronominalen Qualitätsadjektiven an eine auf iššs ausgehende Bildung: apeniššwant-, apeneššuwant- "so beschaffen, ein solcher", kišš̀want- uso beschaffen"; natürlich liegt hier analogische Beeinflussung der want-Bildungen durch die Adverbien auf -šš-an vor, s, oben I d Nr. 7; vgli noch die Anm. 109.

p) die intervokalische Gruppe - $h w-:$

1. mit einfach geschriebenem $-h$ ::

(9) lahwa-, lahhu- "giessen" geht in seinem Paradigma nach einem recht interessánten Gesetz: wenn die Endung vokalisch anlautet, steht gewöhnilich einfach geschriebenes $-h$ - vor dem Wurzelauslaut, wenn dagegen die Endung mit Konsonant anlautet, wird $h$ - doppelt geschrieben; doch wird einfaches $-h$ - auch vor letzteren Endungen geschrieben, wenn der Stamm auf - $a$-auslautet; also: Präs. 3. Sg. lahuwai, lahui usw., Med. lahuwatari, lahuwari, ${ }^{106}$ 3. Pl. lahuwanzi; Prät. 1. Sg. lahuwanun, auch lahun, ${ }^{107}$ 3. Sg. lahuwaiš, lahuwaš, Imp. 3: Sg. Med. lahuwaru, Part. lahuwant, Verbalsubst. lahuwar; dagegen Präs. 2. Sg. lahhutti, Prät. 3. Sg. lahhuš; Imp. 2. Pl. lahhuten; dazu noch arrumaš lahhu- "Kanne zum Úbergiessen des Handwaschwassers"; - Ausnahmen untén Nr. $12 ;{ }^{177}$ a zu idg. "low- wwaschenu (richtiger "loHu- bzw. ( loH w-); demnach mit konsonantischem - $w$ - vor Vokal und mit vokalischem -u- vor Konsonant im Anlaut der Endung, was im Hethitischen noch mit Einführung der vokalischen Stammform in einem Teil des Paradigma kompliziert wưrde; man muss dann idg. 2. Sg. "loHu-th-, 3. Sg. *loHw-ei o. dgl., Part. "loHw-ont- usw. ansetzen;

(10) mijahuwanta- nalt werden॥ mit dem Abstraktum mijahuwandatar "Greisenalter", mijahuwanteš- ialt werden«, zu lesen mijahwant, wohl mit dem Suffix -want- von einem *mijahha- "Gedeihen, Reifeni abgeleitet; ${ }^{108}$

(11) fremd ist wohl šahuihu(i)ššuwali- nlegitim (von Geburt)«, ${ }^{109}$ es zeugt wohl trotzdem von der in Frage stehenden hethitischen Sprechgewohnheit;

${ }^{106}$ Diese Form ist die richtige, lahuwatari Entgleisung nach der mi- Konjugation, aber von dem sekundären vokalischen $(a-)$ Stamm, ähnlich wie Prät. 1. .Sg. lahuwanun.

107 lahun wohl aus urspr. *lahwun, wobel allerdings $-h h-$ zu erwarten wäre, wenn man die Bemerkungen zu idg. * $q$ w- im Kapitel B Pkt. I e in Betracht zieht; demhlach nach dem Stamm lahw(a)- gerichtet.

${ }^{107}$ a Von den nach vorliegenden Regeln nicht régelrecht geschriebenen Formen ist hier Präs. 1. Sg. lahuhhi hervorzuheben; da sie einfaches $-h-$ vor wohl vokalischem $-u$ - aufweist und so in Gegensatz zu 2. Sg. lahhutti tritt; die Erklärung ist nicht schwierig: eine Art Dissimilation des wurzelhaften - $h h$-gegen das suffixale - $h h-$

${ }_{108}$ Anders Kronasser 267: von einem *mijah- (so, mit einfachem - $h$-, was dafür zeugt, wie notwendig unsere Regel ist; die Verba dieses Typus haben nur $-h h-$, von ein Paar ganz vereinzelten Ausnahmen ábgèsehen) walt machen mit deverbalem -want-; da es nur *mijahh- geben konnte, kommt diese Deutung aufs Gleiche: - $h w$ ist erklärungsbedürftig und nur nach unserer Regel wirklich erklärbar.

${ }^{109}$ Luwisch nach Laroche, $D$. louv. 84; da nach ihm -hüiššuwali- luwischem huidwali- 》lebendig“ entspricht, muss es ebenfalls eine Únregelmässigkeit, diesmal in -ššu- (d. h. -ssw-), enthalten, die aber auf die Rechnung des Hethitischen gehen muss, denn das Luwische hat hier eben - $t / d w-$ ! Aber die Bildung ist hybrid, somit manchen Schwankungen und Abweichungen, ausgesetzt, so dass dies 


\section{2. mit doppelt geschriebenem $-h h$-:}

(12) das unter Nr. 9 dargelegte Paradigma kennt ausser einigen Ausnahmen mit unregelmässig gesetztem einfachem $h$ - auch solche mit unregelmässig, d. h. vor konsonantisch zu' sprechendem -w-, doppelt geschriebenem -hh-: je einmal Präs. 3: Sg. lahhuwai, Imp. 2. Pl. lahhuwaten, während die zweite Form einfach als unrichtige bzw. umgekehrte Schreibung für eine. Lautung lahhutten gelten kann,, 10 wird die erstere Form wohl unter dem Einfluss der 2. Sg. lahhutti entstanden sein, vgl. das bei Laroche, $R H A$. 9, fasc. 49, $1948 / 49$, 15 hergestellte lahhuwai, das unmittelbar nach dem Vorbild von lahhutti der vorausgehenden Zeile geschrieben zu sein scheint!

(13) das Paradigma des Wortes für "Feuer», pahhur, kennt mehrere Formen mit $h h h u$ - vor Vokal: so die Nebenform des Nom. Sg. pahhuwar, Gen. pahhuenaš, Dat.-Lok. pahhueni (neben pahhuni), Abl. pahhuenaz (neben pahhunaz), Instr. pahhuenit; dazu die Ableitung pahhuinalli- "Feuerbecken o. dgl.." (neben pahhunalli-); zu idg. *peH-wr, *peH-ur usw. "Feuer"; ${ }^{111}$ die $h h$ Formen sind aus der regelmässigen Vertretung des indogermanischen Laryngals vor der Suffixform *-ur, *un- erklärbar, vor den alten Suffixformen ${ }^{*}-w r$ bzw. *-wōr und *-wen (ursprünglich nur Lok. Sg.) sollte das $h$ - einfách geschrieben sein; analogische Weiterwucherung im Rahmen desselben Paradigmas konnte sehr leicht auch hier das - $h h$ - durchführen; "112

(14) tuhhuwäi- "Rauch", wenn als *tuhhwai- (zweisilbig) zu lesen, kann dưrch die Sippe tuhhā- nkeuchen, Atemnot habeni, tuhhima- iKeuchen, Atemnot, Erstickung! usw. beeinflusst sein, wo kein -w- hinter dem $-h h$ - vorlag; ${ }^{13}$ zu idg. *dhewa ustieben, wirbein; wehen, blasen", schwundstufig *dhuH-;

(15) mit Glossenkeil versehen ist huwahhuwartalla- "Halskette», demnach wohl aus einem anderen indogermanischen Dialekt Anatoliens stammend; aber auch wenn echt hethitisches Wort, kann sein - $h h$ - richtig sein, denn es ist von huhharti. bzw. huwahharti- "Kehle" (richtige Lesung huhhurti-usw.!) abgeleitet, wo die zweite Silbe wohl immer nur vokalisches $-u$ - hatte, so dass -uwa- für -u- steht; ${ }^{114}$

-huiššuwali- kaum gegen unsere Regel benutzt werden kann. Vielleicht ist -ššuwmit der Lautung -ssw- im Munde, der Luwier entstanden, weil sie kein -sw- mehr kannten, seitdem es zu - $t / d w$ - geworden war.

${ }^{210} \mathrm{Vgl}$. dazu Kronasser 35 und 80 , wo natürlich nicht alles einwandfrei dargestelit, wird. Seine Erklärungen machen es deutlich, wie sehr notwendig eine eingehendere Abgrenzung einzelner Erscheinungstypen in der hethitischen Orthographie ist.

111 Zum ursprünglichen Paradigma Pedersen, Hittitisch $187 \mathrm{f} ;$ im Nom. Sg, pahhuwar braucht -war nicht einmal sprachwirklich zu sein, denn sein -wa- kann nur angewandt sein, um eine Aussprache or des einstigen Ausganges -ur anzudeuten!. Vgl. Nr. 15 im Text und Fn. 114.

112 Im Luwischen wurde vielleicht in umgekehrter Richtung ausgeglichen: Nom. Sg. pahur mit einfachem - $h$; doch sind die betreffenden Graphien im Luwischen noch verwickelter, vgl. Laroche, Dilouv. 131! Auch weiss man nicht ganz sicher, ob das Luwische ebensolchem Einfluss von -w-auf vorhergehende Konsonanten in allen denjenigen Fällen wie das Hethitische Raum gab.

${ }^{113}$ Auch ein *tuhhu- als Grundlage von tuhhuwāi- muss einst bestanden haben. 
c) die intervokalische Gruppe -nw-:

1. mit einfach geschriebenem $-n-$ :

(16) unuwā- uschmücken, putzen, herrichten usw.ı mit unuwašha. "Schmucki (zu lesen unw-), zur Etymologie čop, SlR. Lingu. 9, 1956, 47;

2. mit doppelt geschriebenem $-n n-:$ kein nennenswertes Beispiel;

d) die intervokalische Gruppe - $-7 w$ :

1. mit einfach geschriebenem $i$ :

(17)-(21) etymologisch unklar: alwanzahh wbezaubern, behexeni mit alwanzatar "Bezauberung, Behexung" und alwanzena- mzauberhaft, verzaubert" u. a., halwammar "Eifer", palwă- (unklares Verbum), šatwina- "Mörtel aus Lehm und Häcksel«, zuwalwalā- w(Schlange) würgeni u. a.; .

(22) im Suffix steht -lw- mit einfachem -l- etwa bei hattalu- "Riegelu im Gen. ha(t)talwaš und in der Ableitung hatalwā- wverriegeln«, Etymologie un. bekannt;

(23) ähnlich hannitalwana- "Gerichtsgegner" mit hannitalwešš- "Gerichtsgegner werden«, zu hanna- wentscheiden, richten« mit unklaren Ableitungselement (Kompositum?); ${ }^{\text {its }}$

2. mit doppelt geschriebenem -ll-:

(24) halluwā- istreiten, sich zanken" mit halluwāi- "Streit, Zanku usw., von unklarer Herkunft, wenn man iberhaupt mit der Aussprache hallwā- zu rechnen hat, was in diesem Falle äusserst unsicher wäre; es kann sich um Ableitung aus einem Urstamm "hallu- handeln, wobei noch an eine Assimilation aus *-ln-oder *-dl-,*-sl-o. ä. gedacht werden kann;

(25) auch morphologisch ganz unklar ist hallu- stief«, mit Gen. halluwaš; Abl. halluwaz, Nom. Pl. hallueš, auch halluš, aber Akk. Pl. halluwauš und halluwamuš, als ob er von einem Stamm "hálluwu- käme; jedenfalls ist es nicht mit einer ausschliesslich konsonantisches - $w$ - enthaltenden Formengruppe zu rechnen, so dass man analogisch uibertragenes $l l$-ohne. Schwierigkeit berechtigen kann!

(26) von wellu- "Aue, Wiese« war schon oben I a Nr. 58 mit Fn. $65 \mathrm{~d}$ die Rede; der Fall ist also ebenso vom Standpunkt der Stellung des =ll- nach $e$-Vokal wie wegen der Gruppe $l l w$ - unregelmässig, was sicher erst durch eine pasşende Etymologie erklärt werden wird;

e) die intervokalische Gruppe $r w$-:

1. mit einfach geschriebenem $-r$ :

(27) arwā- bzw. aruwā- "sich niederwerfen, anbeten; huldigen"; bis auf die Diathesis identisch mit gr. aráomaí sbete, fluche«, vgl, noçh hom. are $\bar{e}^{\prime}$ .)Gebeti mit langem $a-(* a r w \bar{a})$;

${ }^{114}$ Wohl zu dem Zwecke, úm einem -o- (entstanden vor -r aus - $u$-) klareren Ausdruck zu verleihen. Vgl. Fn. 111; ferner Fn. $152 \mathrm{zu}$ dudduwar- und dort im Text.

115 Ähnlich gebaut ist annitalwa-tar wFähigkeit, Kinder zu gebären«, wenn so gelesen werden muss, von anna- "Mutter«; vgl. zu hannitalwana- noch Kronasser 182 und 193 (kaum weiterführend) und $\mathrm{zu}$ annitalwatar ders. 296.

116 Vgl. Kronasser 85. 


\section{Bojan čop}

(28) šaru- "Beutei in seiner Flexion sowie die Ableitüng šaruwä- nerbeuten, plündern", zu lett. sirt »kriegerische Streif- und Raubzuige machen; verheeren usw.ı usw., mir. serb "iRaub, Frevelı, Čop, Zbornik Fil. fak. II, 1955, 398;

(29) taru- "Holz", zu idg. *doru "Baum", hat sein einfaches $-r$-von den Kasus obliqui mit -rw-, denn im Nom.Akk: Sg. sollte es nach Pkt. I d oben *tarru lauten! !1? $^{11}$

(30) beim Antritt der $w$-Suffixe an $r$-Stämme entsteht unsere Gruppe -rwz. B. in: ešharwant- "blutrot, rot» und Zubehör von ešhar "Blut", dammetarwant- »kraftstrotzend" von "dammetar »ưppigkeit»;

(31)-(34) etymologisch unklar: har (u)wana-- waufhellen; hell werden, dämmern", harwaši- "geheimu, iwaru- "Gabe, Feldanteil usw." mit iwarwā"vals iwaru verleihen, schenken«, tarwä- itanzen, springeni;

(35) wohl luwisch ist warwalan- "Same, Nachkommenschaft";

2. mit doppelt, geschriebenem -rr-: kein nennenswertes Beispiel.

Die Untersuchung hat gezeigt, dass unsere La u te vor $-w$ - normal einfach geschrieben werden: von den 35 untersuchten Fällen fügen sich dieser Regel Nr. 1-4, 9-11, 16, 17-23, 27-35; also 24 Fälle, die aber leicht vermehrt werden könnten; der Regel widerstreben jedoch ziemlich viele Beispiele, die in folgende Kategorien zerfallen:

1. Fälle mit Flexionsformen, wo der Stammauslaut $-u$ - mit $-w$ - wechselt: aššu- Nr. 5 - lahhu- Nr. 12 - hallu- Nr. 25(?) und wellu- Nr. 26 (doch auch mit -e- vor - (ll!); ähnlich pahhur Nr. 13;

2. Fälle, die von $u$-Stämmen mit nach Pkt: 1 geregeltem Paradigma ausgegangen sind: haššuwā- $\mathrm{Nr}$ ' 6 - halluwā- Nr. 24;

3. Fälle, die von Urformen mit doppelt geschriebenem Auslaut mittels der $w$-Suffixe abgeleitet sind: apeniššuwant: und kiššuwant- Nr. 8;

4. Fälle, die neben sich etymologisch verwandte Bildungen ohne das $w$-Suffix haben: tuhhuwäi- Nr. 14;

5. kein $\dot{w}$-Laut kann für huwahhuwartalla $\mathrm{Nr} .15$ angenommen werden, da es wohl huhhurtalla- gesprochen wurde;

6. eine ganz vereinzelte Entgleisung ist $h u-u-i s ̌-s ̌ u-u-i z-z i$ Nr. 7.

Von diesen sechs Kategorien kommen die letzteren zwei natuirlich als völlig aus dem Rahmen fallend für unsere Untersuchung nicht mehr in Betracht; die übrigen vier sind aber derart, dass sie sich ganz glatt mittels analogischer ṫbertragung des doppelt geschriebenen Konsonanten auf Formen ohne $-w$ - in solche mit diesem Konsonant erklären lassen; $m$. a. W., es gibt keinen isolierten Fall, wo der doppelt geschriebene IKonsonant vor kon-, sonantischem $-w$. stünde; oder positiv sprechend, die sechs Konsonanten $s, h$; $\eta, m, l, r$ werden vor konsonantischem -w regelmässig einfach geschrieben. Auch diese Regel fusst auf einer wirklichen Sprechgewohnheit der Hethiter,

${ }_{117}$ Allerdings könnte man an eine distinktive Schreibung denken, da es auch ein tarru- "Bauch" gibt, vgl. zu ähnlichen Versuchen, hethitische orthographische Willküren $\mathrm{zu}$ erkiären, Kronasser $14 \mathrm{f}$; f freilich ist Annahme solcher willkürlicher distinktiver Schreibungen wohl nur Folge der Kommodität derjenigen, die sich nicht in die phonetische usw. Grundlage derselben vertiefen wollen. 
denn es ist durch nichts zu erweisen, dass die Schrift selbst und allein die Schreiber dazu gedrängt hätte. Und wir können hinzuftugen, dass sich diese Einfachschreibung auch schon im Kapitel B, Plkt. II a bei der Lautgruppe idg. Tenuis $+w$ bzw. bei idg. " $q$ w beobachten liess; der Parallelismus kann nicht zufällig sein, man muss annehmen, dass vor dem Konsonant $-w$ - jeder andere Konsonant soweit reduziert wurde, dass er einfach geschrieben werden musste. Weiteres im Kapitel F und J.

III. Mit obigen Feststellungen könnten wir schon unsere Untersuchung iiber die schriftliche Behandlung der untersuchten sechs Laute in ihren wichtigsten Stellungen schliessen. Denn dadurch wurde beinahe die Hälfte aller möglichen Situationen erforscht. Aber die übrige Hälfte drängt" auch zu einer. wenn auch ganz kurzen Behandlung; so werden wir hier aus dem iibriggebliebenen Material noch zwei Fragen aussondern und einer möglichst kurzen Untersuchung unterziehen:"a) die Stellung unserè sechs Laute hinter einem wenigstens vorhistorisch unbetonten kurzen Vokal (ausgenommen $e$ ) und b) die stellung der. selben Konsonanten vor dem Konsonant $-j$. Beide Fragen, vor allem die erstere, sind überaus schwierig, doch ist es gewiss in mehreren Richtungen von grossem Nutzen, auch eine provișorișche Antwort darauf zu geben zu suchen.

a) die Laute $s,{ }^{117} \mathrm{a} n, m, l, r$ in der Stellung nach einem ursprünglich (ursprachlich) unbetonten kurzen Vokal (*e scheidet aus, vgl. Pkt. I a!); der Ausdruck sursprünglich» ist insofern hier am Platze, als es sich um Fälle handelt, wo man wenigstens für eine vorhistorische Periode - die doch nicht unumgänglich mit der ursprachlichen identisch sein muss - die Akzentstelle genau festlegen; kann; im historischen Hethitisch "kann die Akzentstelle; muss aber nicht dieselbe, geblieben sein, denn über die Akzentregelung in dieser Sprache wissen wir iiberhaupt nichts; ${ }^{118}$ wir behandein folgende ziem-

${ }^{117}$ Von $h$ darf in diesem Zusammenhang abgesehen werden, denn es ist um diesen Konsonant ganz besonders bestellt, ausserdem kommen wir darauf noch im Kapitel E zuruick.

${ }_{118}$ Trotz aller Bedenken, die man dagegen äussern kann; wird man jedoch annehmen können, dass die sog. Plene-Schreibung der. Vokale wenigstens zum Teil, so vor allem in den Endsilben der Wörter, auf die Akzentstelle hindeutet; dafür spricht einerseits die Tatsache, dass man solche auf Endsilben beschränkte PleneSchreibung nur in gewissen recht altertümlich aussehenden indogermanischen Wörtern antrifft, wo es sich ganz leicht um Reste ursprachlicher Oxytonierung handeln kann; vgl. dazu unten im Text, Pkt. III a Nr. 6 (šarāa aus *ser-ó), vor allem aber Pkt. IV apā-, tagā $i$, sowie die Flexion von tekan )Erde« überhaupt (Gen.

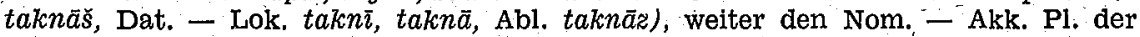
Neutra auf $-r$ - und $-r / n$-, wo man oft $-\bar{a} r$ hat, was ganz einfach auf idg. *-o'r zurückgehen kann; leider kann man hier auch eine andere Auffassung vertreten, s. Pkt. I d Nr. 22 und Fn. 98; solche Endbetonung kann auch erhalten sein, wenn sonst regelmässig der Wortton von der Uitima zurückgezogen wurde; vgl. zu solchen ríckständigen Fällen das Slovenische, wo in manchen urslavischen Oxytona der Akzent auf der letzten Silbe blieb; vgl. maglà "Nebel trotz nóga "Fuss» (ursl. *maglá, *nogá) usw.; andrerseits scheint der,Umstand, dass gewisse normal betonte Monosyllaba Plene-Schreibung des einzigen Vokals aufweisen, ebenfalls für unsere 
lich klare Fälle (Anordnung nach dem Charakter der Beispiele bzw. alphabetisch):

(1) aräi $i$ usich erheben", aus idg. "oréje- zu gr. oréomai "breche auf"; dagegen das transitive arā- "(Pferd) zum Stehen bringen, hemmen, zurückhaltenu aus idg. *orä-;

(2) hamešha- "Frühjahr", zu ahd. amar(o), amari, nhd. Emmer "triticum dicoccum॥ aus *ameza $(n)$-, demnach auch heth. ursprünglich *HomesHo-; C̈op, SlR. Lingu. 8, 1955, 30;

(3) išhamāi- usingen" und išhamäi- "Gesang, Lied", beide mit Suffixen, die Akzent auf sich trugen: Verbum mit *éje-, Substantivum mit *éi/oi- (vgl. gr. peithō') o. dgl., zur Etymologie Benveniste, BSL. 50/1, 1954, 39 f.; C̆op, Die Sprache 6, 1960, 5;

(4) maninku- ikurz, nahe», zu lat. prop-inquus usw., Benveniste, BSL. 50/1, 1954, 41; doch scheint mir am geratensten, im ersten Glied, im Gegensatz zu Benveniste, hethitische Entsprechung von idg. * $m \partial-\hat{n}$. "Hand" zu sehen, ursprünglich demnach "bis zur Hand reichend", vgl. lat. com-minus whandgemein, ganz in der Nähen; zum Akzent - im Hethitischen handelt es sich um vollstufiges "-énqw:! - vgl. ai. praty-áñc- ızugewandtı usw.;

(5) paräi- whauchen, blasen, wehen usw.u, aus idg. "p(o)réje- (oder

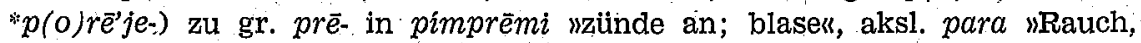
Dampfi usw., vgl. Hendriksen, Unters. ïb. die Bed. des Heth. f. d. Laryngaltheorie 48 mit etwas anderer Analyse und laryngalistischer Konzeption des Suffixalelementes;

(6) $\breve{a r} \bar{a}$ iempor, hinauf, herauf; auf etwas hinauf ist zwar ohne ausseranatolische Verwandte, muss aber angesichts des danebenstehenden šar noben, oberhalb, darauf; auf, oben in; usw." auf ein zweisilbiges Adverbium zurückgeführt werden; wo der Akzent auf der letzten Silbe lag; es ișt übrigens ganz akzeptabel, in $-\bar{a}$ die indogermanische Postposition ${ }^{*} \bar{o} \cdot$ zu sehen, die den Akzent auf sich zog; 119

(7) damašš- "drücken, drängen», zu gr. edámassa ubändigte॥, muss auf eine Urform mit dem Akzent auf zweiter oder noch weiter gegen Ende liegender Silbe zurückgehen; aber die Nebenform damešš- zeugt von einer komplizierten Vorgeschichte dieses Verbumś, so dass man mit einfacher Grund-

Annahme zu sprechen, dass in solchen Fällen diese schreibmethode auf eine verstärkte bzw. verlängerte Aussprache des betonten Vokals hinweist; wenn Kronasser dies an der Hand vermeintlicher Gegenbeispiele wie $n u$ sundi abzulehnen geneigt ist (S. $28 \mathrm{f}$.), so ist dem entgegenzuhalten, dass $u$. a, gerade $n u$ ein kaum besonders stark betontes Wort ist, vielmehr gewöhnlich proklitisch bzw. (bei Antritt der Enklitika) zwar führendes Wörtchen, das aber wieder, seine Selbständigkeit und damit Einsilbigkeit verloren hat. Dass Schwierigkeiten auch bei unserer Auffassung bestehen bleiben, ist zuzugeben, die danebenstehende Einfachschreibung der in Frage stehenden 'Vokale darf aber ebensowenig als auf Kürze hindeutend erklärt werden wie bei der gelegentlichen Einfachschreibung der urspringlichen Tenues dieser Umstand als Zeichen für deren Zusammenfall mit Mediae ausgelegt werden darf.

119 Oder Nachahmung des altererbten parā worwärts, hervor, hinaus usw.«, das aber dann nicht aus *pro und einsilbig sein könnte! 
form kaum auskommen kann; demnach Vermischung von *dema-oder *domo. mit dem Kausativum "doméje-? vgl. ähnliche Prozesse in lat. domō; s. Fn. 91; doch macht die Bedeutung Schwierigkeiten!

(8) in der Flexion der abgeleiteten neutralen $n$ - und $r / n$-Stämme war nach Ausweis anderer indogermanischer Sprachen der Akzent oft an die Wurzelsilbe gebunden, ebenso bei den abgeleiteten Stämmen auf $-s-$ und $-l-,-r-$; daher die Unbetontheit des suffixalen Vokals und Einfachschreibung des stammauslautenden Konsonantes: irman- (Dat.-Lok. irmani) wKrankheit», mehun- zu mehur "Zeit», šehun- zu šehur "Urin", uddan- zu uttar "Wort, Rede usw.», kalmuš- "Lituus, Krummstab", aššul- "Heil, Wohlergehen«, iš̆hiul- (nur selten išhiull-) „Bindung, Verpflichtung, Vorschrift, Vertrag" u. ä.; huppar- wSchale, Terrine», aniur " (vorgeschriebene) Leistung, Opferritus, Ritual" und viele andęre ähnlich gebaute Neutra, dazu kurur- "feindlich, Feind, Feindschaft" usw.;

(9) aši „der betreffendeu soll nach Pedersen, Hittitisch 60 aus dem Nom. Sg. aš wder» und deiktischer Partikel *i zusammengesetzt sein, wobei diè Akzentuierung von gr. houtos-i beachtet werden soll; ebenso nach P. un-i ijener, der dau, wo ein Akk. Sg. "un stecken soll; ,vgl, noch zu einem "an-i sdieseri oben Fn. 93 b!

(10) in der infigierten Verbalklasse (Friedrich, Heth. El. $\mathrm{I}^{2} \$ 167$, Klasse I5) wird das infigierte $-n-$ auch nach einem Vokal einfach geschrieben: hunink- "zerschlagen, beschädigen", ninink- wheben, hochnehmen, (Truppen) aufbieten usw. "12n zum Akzent auf dem vollstufigen Infix idg. "-né- vgl. ai. yunák-ti wverbindet»;

(11) das Verbalsuffix -nu- (Klasse I 7, Friedrich, Heth. El. $I^{i} \$ 169$ ) wird nach vokalischem Auslaut des Grundstammes immer einfach geschrieben von einigen recht unbedeutenden Ausnahmen abgesehen; ${ }^{121}$ so z. B. nach $-a$ - in anna-nu- sunterrichten, ausbilden, (Tiere) dressieren ", ${ }^{122}$ kartimmija-nu- szornig machen, erzürnenu zu kartimmija uzürnen, grollen», karuššija-nu- wzum Schweigen veranlassen zu karuššija- ischweigen", nach :- - in hali-nu- uzum. Niederknien veranlassen " zu halija- miederknien", hui-nu- (neben hue-nu- und $h u-n u$ - $)^{123}$ uzum Laufen veranlassen« zu $h u w \bar{a} i-h \bar{u} j a-$ waufen, fliehen, entkommen", tani-nu- weinrichten, ordnen" mit unklarem Grundstamm, zai-nu und zi-nu- whinüberschaffen, hinüberbringeni zu zäi- vïberschreiten», nach $-u$ -

${ }_{120}$ Richtige Etymologie von ninink- bei Benveniste, BSL. 50/1, 1954, 40 f. (zu lit. $n i k-t i$ usich in eine schnelle Bewegung versetzenu usw.). Warum Kronasser 25 noch auf dem alten standpunkt beharrt, ist mir unklar.

'121 So das noch etwas unklare tinnu- (auch tinu-) wzum stillstand bringen, lähmeni, wo aber der Grundstamm unbelegt ist.

${ }_{122}$ Zur Etymologie unten im Text Pkt. III b am Ende mit Fn. 146 und Fn. 133.

${ }^{123}$ Da der Grundstamm wahrscheinlich eigentlich $h w e j$ - lautete, worüber ziemlich richtig Kronasser 39 (nur möchte ich nicht das ganze Paradigma einheitlich. lesen!), ist es bei dessen Kausativum, kaum zu entscheiden, ob hui-nu- die Reduktionsstufe der. Wurzel darstellt oder nur schlechte Schreibung fuir hue-nuist, und umgekehrt, ob hue-nu-als ${ }^{*} H w e i-n u$ zu deuten ist und zu Pkt. I a gehört oder statt hui-nu- nach hweja- umgefärbt ist. 
$d u d d u$-nu- »begnadigen $z u$ duddu- ugnädig verwalten«; usw.; zum Akzent auf dem vollstufigen Suffix vgl. ai. sunō'-ti upresst ausi;

(12) hier könnte man noch die Medialenđungen -hhari, -ttari, -ntari, -hharu, -ttaru, -ntaru - d. h. diejenigen der mi-Konjugation ${ }^{124}$ anschliessen, da sie nach Ausweis anderer indogermanischer Sprachen vor dem $-r$ - sicher einst unbetonte kurze, besser reduzierte Vokale enthielten; die Einfachschreibung des -r-rührt demnach zum Teil wohl von dieser Tatsache her; zu einer weiteren Erklärung oben Plkt. I b Nr. 8!

Es kann hier Halt gemacht werden; die angeführten Beispiele sind sicher insofern beweiskräftig, als sie wenigstens als A r beit s hy o these den Satz auszusprechen gestatten: $n$ ach einem in der Ursprache bzw. kurz nach der Lösung der sprachgemeinschaft unbetonten kurzen (ach reduzierten) Vokal stehende Konsonanten $s, n, m, l, r$ werden in der historischen Zeit gew öhnlich einfach geschrieben. Diese Aussage zieht gewisse Folgen nach sich:

1. die oben Pkt. I d erkannte Regel, dass nach idg. kurzen Vokalen mit Ausnahme von $* e !-$ stehende Konsonanten $s, h, n, m, l, r$ im Hethitischen doppelt geschrieben werden, kann also nur diejenigen Fälle betreffen, die vor dem in Frage stehenden Konsonanten, $d . h$. auf der indogermanischen Kürze davor betont wurden; eine Reihe von dort angegebenen Beispielen fügt sich dieser Einschränkung:-das Femininsuffix -ššara- Nr. 4, vgl. idg. *swésor, die Pronominaladverbia kiššan usw. Nr. 7, da aus einstigem "kis usw. entstanden (vgl. Pkt. II Nr. 8!), *wanna Nr. 9, das aus idg. *w-ono- entstanden ist, "anna- Nr. 10, vgl. gr. énē «der übermorgige Tag», lammar Nr. 13 aus *nomr, iškalla- nach der hi-Konjugation Nr. 16, malla- Nr. 18, arra- Nr. 20; šarra- Nr. 21, vgl. zu letzteren vier Fn. 97, die Endung arri Nr. 22, wohl auch das Suffix - $(t)$ talla- Nr. 19 aus idg. *-té/ót-;125 bei anderen ist keine genaue Akzentbestimmung möglich; so bei paššila- Nr. 2 (kann trotz der Schwundstufe in der Wurzel Akzent zurückgezogen haben); kuwanna(n)- Nr. 11 (gr. kyanos ist keine Garantie fuir ehemalige Betontheit des $k u$ auch im Hethitischen), imma Nr. 14 (Grundform nicht bestimmbar), bei dem Suffix -mmar Nr. 15 (stimmt zu unserer Regel, wenn es an Oxytona getreten ist); ${ }^{125}$ a andere stimmen nicht:

a) die adjektivischen $u$-Stämme $a s ̌ s ̌$ - (Pkt. I c Nr. 1), daššu- Nr. 3 , die ursprachlich oxytoniert waren; doch muss man bedenken, dass es neben ašš - im Luwischen ein wašu- gibt, das zu ai. vásu- (paroxytoniert!) gehört, das auf die Lautgeschichte von "esu- ( $>a a_{s ̌ s} u$-) Einfluss ausüben konnte; dass ferner $a s ̌ s ̌ l u$ auch substantivisch vorkommt und hier ursprünglich wohl paroxytoniert war;

124. Dagegen wird man die Endungen der hi-Konjugation, -ari, -aru am sichersten, als idg. * $\bar{a} \mathrm{x}-r+-i$ erklären dürfen, oben Pkt. I b Nr. 8.

${ }^{125}$ Auf die Suffixbetonung weist ja schon der e-Vokalismus von sl. -tel-.

${ }^{125}$ a Auch tăn pedašsahh- Nr. 5 gehört zu den unsicheren Fällen, kann aber schon wieder in Ordnung sein, wenn man an ai. padá- ischritt, Tritt, Fussstapfe denkt. 
ß) ähnliche Schwierigkeiten bereitet uns išš Nr. 1, da es als schwundstufiger Stamm unbetont gewesen sein muss;

r) über genaue Vorgeschichte von ištamašš und damašš- Nr. 6 wissen wir nichts, der Vokal vor -šš- wạr jedoch schwundstufig und unbetont;

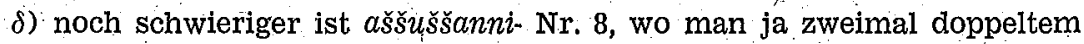
-šš- begegnet, dazu noch doppeltem -nn-; das letztere ist freilich mit dem Einfluss anderer Bildungen auf $-n i^{-126}$ gut erklärbar; von den beiden $-s ̌-k a n n$ jedoch nur das erstere odër das zweite regelrecht sein; ${ }^{127}$

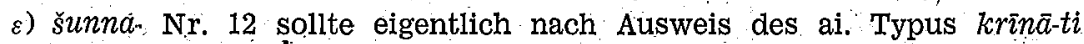
"kauft" mit einfachem - $n$ - geschrieben sein, doch muss man bedenken, dass dieser Typus im Hethitischen auch sonst eigene Wege ging, so z. B. flektiert unser Verbum nach der hi-Konjugation, während die damit engstens verwandten zwei Typen, der mit Infix -nin- und der auf -nu-, nach der mi-Konjugation gehen! das - nn- wird demnach dem Einfluss von hanna- sentscheiden; richten", nanna - "treiben", šanna- "verschweigen, verheimlichen", unna- whertreiben, herschicken" usw. zu verdanken sein;

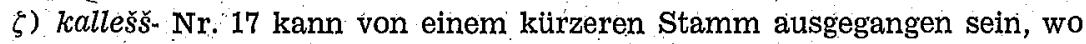
das $-l l$ - lautgesetzlich war, etwa *kalla (nach der hi-Konjugation), wozu die Formen .Prät. 3. Sg. 'kallišta und Imp. 3. Sg. kallišdu ausgezeichnet passen würden!

Zu dieser Einsschränkung müssten auch oben Pkt. I d 2 angeführten Beispiele stimmen; so wohl išna- neben iššana- Nr. 23, da aus einem *no-Partizip mit-substantivischer Akzentzurückziehung, pahš- neben pahhaš- Nr. 27 mit dem in vollstufiger Stammform normalen Akzent; unserer Einschränkung fügen sich jedoch nicht? šašnu- mit šašs̆anu- und ašnu- mit aššanu- Nr. 25, vgl. hijer oben Nr. 11; wohl auch nicht häšsik-, tiššakk- und tiššikk- Nr. 26, da das Iterativsuffix ursprünglich auf dem thematischen Vokal betont war.

Diese Durchmusterung der Beispiele, die einigermassen klar sind, was die ursprüngliche Akzentstelle anbelangt, zeigt, dass eigentlich alle nicht stimmenden Fälle den Sibilant enthalten; ein faches -s- haben wir nur in kalmuš- hier oben Nr. 8 und in aši Nr. 9 gesehen; man wird demzufolge schon wieder gerade die laut(geschicht)liche Sonderstellung des $s$-Lautes für diese Unregelmässigkeiten verantwortlich machen müssen. Man vergleiche dazu noch die Feștstellungen über diesen Konsonant oben Pkt. I $a$ und $b$ !

2. wenn derselbe Stamm bzw, dieselbe Wurzel in verschieden akzentuierten Bildungen auftritt, so muss sich der Akżentunterschied auch an der Schreibweise des wurzelauslautenden Konsonanten ausgewirkt haben; freilich wurden wohl die meisten derartigen Fälle aus dem lebendigen Gebrauch durch verschiedene Ummodelungen ausgemerzt: lautliche Angleichung, orthographi-

${ }^{126} \mathrm{Zu}$ solchen vgl. zuletzt Kronasser 145 und $221 \mathrm{ff} .-$ (churritisches und anderweitiges Material.)

${ }_{127}$ Es kann sich auch um eine Art Lautsubstitution handeln, da ja das Hethitísche das Wort in churritischer Lautgestalt übernommen haben muss; heth. -ssfür churr. -s-. 
sche Nivellierung úsw.; dennoch kann man z. B, an dem Paare kuššan „Lohn, Sold; Preis" - kušata "Brautpreis" die alte Verteilung noch ablesen: das erste Wort war sicher auf der Wurzel betont, demzufolge sein -s- gedoppelt, s. oben Pkt. I b Nr. 12; kušata dagegen gehört wohl zum Typus auf -atar, wo schwerlich die Wurzel betont war; ${ }^{128}$ ein ähnliches Verhältnis muss auch in der folgenden Wortgruppe bestanden haben: wurzelbetont šanna- "verschweigen, verheimlichen " (eig. uabsondern ${ }^{129}$ und šannapi šannapi. svereinzelt, verstreut, hier und da mit Zubehör - suffixbetont šani- wein und derselbe« und šanezzi- usüss, wohlschmeckend, wohlriechend; erstklassig, feini (eig. "gesondertii). ${ }^{17 \% 9}-129 \mathrm{C}$

Zusammenfassend kann man sagen: die hier untersuchte Stellung von $s, n, m, l, r$ nach einem einst unbetonten kurzen Vokal hat gewöhnlich Einfachschreibung zur Folge, nur die Belege mit $s$ werden auch hier, vor allem wenn das s- nach dem ersten Vokal des Wortes steht, durch Doppelschreibung ausgezeichnet. Diese provisorische, Regel bedarf aber noch eingehender Untersuchungen.

b) die Laute $s, h, n, m, l, r$ vor konsonantischem $j$-Laut: ${ }^{130}$

${ }^{128}$ Darauf scheint für die historische Zeit selbst die häufige Plene-Schreibung des - $a$ - vor - tar zu deuten; Beispiele z. B. neuerdings bei Kronasser 292 ff. (-a-a-tar auch bei konsonantischen Stämmen, demnach kaum mit langvokalischen in (ausschliesslichen) Zusammenhang zu bringen!).

${ }^{129}$ Das Verbum šanna hat versuchweise schon Götze, Lg. 11, 1935, 190 mit dem Numerale šanna- seinsw verbunden; sein Zweifel in Hinblick auf den primären Charakter des genannten Verbums ist nicht ernst zu nehmen, denn es kann sich in beiden Fällen, beim Verbum wie beim Numerale, um parallele und unter sich unabhängige ursprachliche Entwicklungen aus gemeinsamer Wurzel handeln. Und die Verbindung des verbalen šanna- mit šanezzi- und idg. *sen-i usw. ofür sich, abgesonderti steht schon bei Lohmann, IF. 51, 1933, 326 Fn. 1 (vach Ehelolf). Es ist aber ganz natürlich, alle diese Kombinationen zusammenzuhalten und aus den im Text angeführten 'Wörtern eine etymologisch einheitliche Gruppe zusammenżustellen.

Mehr daruber demnächst.

129a Also urspr. *soni- o. ä. und *soné-tjo- o. dgl: wie at. amā' szu Hause und amä'-tya- »Hausgenosser!

${ }^{129} \mathrm{~b} \mathrm{Zu}$ erwähnen ist noch das Verhältnis von *aaluki- in zaluganu- muruickhalten, verzögerni usw. zu *zalla- „Trabi (urspr, slangsame Gangart oder sogar Adj. vlangsam(), wenn das letztere hethitisch-indogermanisch ist (s. oben Kapitel A. Nr. 22 und Fn. 8); a. a. O. genannte Bildungen auf $-u$-ki- können nicht von unserer Regel ausgeschlossen werden, vgl. haluki- und daluki- mit einfachem - $l$, demnach alle mit Akzent entweder auf $-u$ - oder auf dem Stammauslaut.

${ }^{129} \mathrm{c}$ Ein sehr gutes Beispiel ist auch tapuwaš »Rippe, Seiteর: Gen. Sg. tapuwašsaš, Ableitung tapuwaššant- gegen Dat. - Lok. Sg. -tapuša reflektieren hochaltertümliches idg. Suffix *-wós- (betonte Vollstufe) gegen *-us-' (unbetonte Schwundstufe)!

${ }^{130} \mathrm{Zu}$ achten ist, dass man in diesen Fällen nicht ganz zuversichtlich sagen kann, ob das einst sicher konsonantische $-j$ - in der historischen Zeit so blieb oder aber vokalisiert, wurde wie etwa im Lateinischen, z. B. in medius. Der Ausdruck »der Konsonant $j k$ ist also vor allem in historischem Sinne zu nehmen. Die angeführten Fälle sind so gewählt, dass diejenigen mit - - vor der $j$-Gruppe, ebenso auch diëjenigen mit nachweislich ursprünglich langem Vokal vor der $j$-Gruppe ausgeschlos- 
1. die intervokalische Lautgruppe $-s j$ :

a) mit einfachem $-s ̌ s:$

(1) išijahh- naufspüren, offenkundig machen«; bisher unbekannter Etymologie; m. E. zu idg. *ais-, *is- "wünschen, begehren, aufsuchen॥; zur Struk tur vgl. manijahh- unten $\mathrm{Nr} .8$;

(2) tuhušija- iabwarten, ruhig zusehen, gewähren lassenı, mit luw. dahušija- ds. uraltes idg. Verbum auf ${ }^{*} j e / 0$ - von einer laryngalhaltigen Wurzel, am besten zu ai. túšyati uberuhigt sich, ist zufriedenı und Verwandten, Näheres anderswo;

B) mit doppeltem -šš:

(3) hališšija- "(in Metall) einfassen, einrahmen", denominativ von *hališ(besser *hališš) "Rahmen, Einfassungu, von -šš- abgesehen identisch mit hati"HḦ̈rde für Grossvieh, Mauer; Mondhof "; ${ }^{131}$ das -ššs kann also vom Grundwort herrühren:

(4) karuššija- ischweigen; gleichgültig sein, ruhig zusehenu, aus idg. *gworus- zu arm. kornčhim "perdersi, morire, distruggerși usw.u, korust "perdita, danno, strage, uccisione usw." u. a., wozu von einem kürzeren Grundstamm noch heth. karija- "(ein Heer) ins Nachtquartier legen; rasten, übernachtenı usw.; Čop, Zbornik Fil. fak. II, 1955, 395 (die ganze idg. Sippe 393 ff.);

2. die intervokalische Lautgruppe $-h j-$ : hier muss man beachten, dasis die ursprachliche Lautgruppe $* H j$ - schon voreinzelsprachlich sein $H-H$ - unter Dehnung des vorausgehenden Vokals verlor; ins Hethitische konnte also kein ererbtes $h j$ - gelangen; wohl aber kann das Hethitische hie und da aus verwandten Formen mit gehaltenem $-h$ - die Lautgruppe - $h j$ - wieder hergestellt oder auf Grund der auf $-h$-auslautenden Wurzeln mittels $j$-haltiger Suffixe sie neu aufgebaut haben. Die Fälle müssen auf jeden Fall sehr selten sein; so etwa (mit einfachem $-h$-):

(5) lahija- uschlagen", wenn als lahja- zu lesen, von schwieriger Etymologie, wahrscheinlich einfach onomatopoetisch;

(6) Dat,-Lok. Sg. zu manijahhäi- "Leitung, Verwaltungw lautet neben manijahhija auch manijahija; hier als -hja zu lesen? ${ }^{132}$

3 . die intervokalische Lautgruppe $-n j$; nur einfaches $-n-$ :

(7) anija w wirken, schaffen, arbeiten usw." mit Ableitungen anijatt"Leistung" und aniur "(vorgeschriebene) Leistung, Opferritus, Ritual", wahrscheinlich zu "anna- "jener"; ;

sen blieben. Freilich muss man dabei in Betracht ziehen, dass die meisten Fälle im Urindogermanischen den Akzent auf Silben hinter der $j$-Gruppe trugen, so dass eigentlich sehr. wenige wirklich stichhaltig sind.

${ }_{131}$ Vgl. Abl. hališša wvon der Einfassungu als Grundwort zu unserem Verbum bei Kronasser 328 , der aber weiter an hali- anknüpfen sollte.

${ }^{132}$ Es sollten noch einige Verba mit - $h h i j$ - angeführt werden, so etwa $l a h h i j \vec{a}$ "Krieg führen, bekriegen《 zu lahha-. "Feldzug«, zahhija- »bekämpfen« u. a.; aber das letztangeführte Wort ist von $\approx \dot{a} h h \bar{a} i$ - nSchlacht, Kampfu ausgegangen, lahhija $\overrightarrow{-}$ - kann aber auch nicht direkt zu lahha- führen, denn in diesem Falle erwartete mản *lahha $\overline{-}$ ! So fand ich keinen guten Fall, wo ein vorhistorisches * $h h j$ - stlinde.

${ }_{133}$ So schon Machek; Die Sprache 4, 1958, $76 \mathrm{ff}$. mit guten baltoslavischen Parallelen, vgl. vor allem lit. anioti stun, (etwas) treiben« von anas sjener(. Vgl. noch 
(8) manijahh- veinhändigen, übergeben, zuteilen; überlassen; verwaiten usw." mit Ablèitungen wie manijahhäi- (oben Nr. 6), manijahhatalla- "Ver" walter, Statthalteri u. a., zu idg. " $m \partial-n$ - "Hand», vgl. oben Pkt. III a Nr. 4 und zur Bildung hier Nr. $1 ;^{134}$

(9) das Verbalsuffix -anija , zum Teil auf nòminalen Nasalstämmen aufgebaut, so armanija- »erkranken« neben irmanija- »krank werden" zu irman

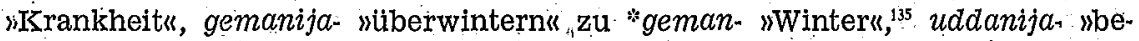
sprechen, beschwören, bezaubern« zu uttar, uddan- "Wort, Rede usw.", zum Teil verselbștändigtes Konglutinat, so tešhaniija- sim Traume erscheinenu. zu tešha- "Schlaf, Traumu;

4. die intervokalische Lautgruppe $-m j$-:

a) mit einfachem - $m$ - nur:

(10) dudáumijahh ntaub machen" und duddumijant- staub», wenn duddumj- zu lesen, zu duddumi ntaubu;

(10a) amijar- oder amijara- "Kanal", ${ }^{135 a}$ zu gr. amára iGraben, Kanal, Furche«, kypr, amira-phi, ${ }^{135 \mathrm{~b}}$ wohl indogermanisch, aber kaum auf einem *jam(so ist die Wurzel für ugraben« bei Pokorny, Idg. EW. 502 angesetzt) fussend, da im Hethitischen jede Spur von $j$ - fehit; ${ }^{135} \mathrm{c}$

$\beta_{i}$ ) mit doppeltem $-m m$ :

(11) immija ${ }^{136}$ mischen«, wenn immja zu lesen, was immerhin sehr unsicher ist, solange keine gute Etymologie zur Verfügung steht; gegen ein "im-je/o- o. dgl. scheint u. a. auch die Schreibung der 2. Sg. immeatti zu sprechen; demnach vielleicht urspr. Láutung *immeja-?

(12) kartimmijä- wzïnen, grollen" mit Zubehör, zu kard-"Herz», doch mit sehr. unklarem Zwischenelement, ${ }^{137}$ schon deswegen ganz unsicheres Beispiel, da nicht notwendig mit altem $-m j ;$;

unten Pkt. III b am Ende zu weiteren Verwandten, die tatsächlich das doppelte $-n n$ - aufweisen.

${ }^{134}$ Ein weiteres Beispiel des Suffixkonglutinates -j-ahh- ist kururijahh- $)$ bekämpfen, bekriegen; Krieg führen«; hier steht daneben kururija- ufeindlich sein« Nr. 23, doch muss das nicht die Basis zur Ausbildung für die $-j$-ahh- Erweiterung darstellen; vielmehr wird man von Adjektiven auf -jo- ausgehen dürfen.

${ }^{135} \mathrm{~S}$. oben Pkt. I a Nr. 47 mit der. Fn. 65 ; gemanija $=$ gr. kheimaino stürmische.

${ }^{135}$ a Zuletzt zur formalen, Seite Kronasser 186 und 271.

135. Zur griechischen Gruppe und deren Beziehungen zum hethitischen Wort s. Frisk, Gr, $E W$. I 86 und vor allem Neumann, Unters, z. Weiterleben heth. $u$. luw. Sprachguites in hell. $u$. röm. Zeit $91 \mathrm{f}$.

${ }^{135} \mathrm{c}$ Bekanntlich wird $j$ - vor $a$-Vokal im Hethitischen erhalten. Die $j$-Form der indogermanischen Wurzel ist jedoch nur auf Grund der slavischen Gegebenheiten angesetzt worden, wo jedoch derartige Erscheinungen sehr unsicher sind, da auch prothetisches $j$ - entweder alt genug ist oder aber analogische U̇bertragung hinter *van- vorliegt. Und endlich kann man auch mit einem *ēma auskommen.

${ }^{136}$ Nur selten steht daneben imija-, das sich unserer Regel fugte. Für das doppelte $-m m$ - kann aber vielleicht auch Iter. ${ }^{*} i m m i s k$ - bestimmend gewesen sein.

137. Bekannt ist Analyse bei Pedersen, Hittitisch 40 , wonach $-m m$ - von einem Part. auf *-mno- herruhrt. Anders Kronasser 179, jedenfalls besser (zugrunde liege ein Abstraktum *kartimma-). 
(13) vgl. noch wannummija- oben Pkt. Id Nr. 9; auch hier muss es sich nicht eben um alte Lautgruppe $-m j$ - handeln;

5. die intervokalische Lautgruppe $-j$ :

a) mit einfachem -l-:

(14) halija- iniederknien«, wahrscheinlich zur idg. Wurzel "*el- ibiegen", demnach aus idg. ${ }^{*} \mathrm{He}$-je/O-;138

(14a) hulija- "Wolle», Nebenform zu hulana- Pkt. I b Nr. 2, vgl. oben Fn. 72 genannte Arbeit von Friedrich; vgl. ai. văla- ischweif(haar), Haarsieb" und lit. valai "Schweifhaar des Pferdes" direkt von der Wurzel; die Urform füs heth. Wort mehrdeutig. (vgl. Friedrich);

(15) tulija- "Ratsversammlung, Gerichtssitzung", wenn indogermanissch,139 dann zu idg. *tulo- (mit kurzem und langem $-u$-) bei Pokorny, Idg. $E W .1081$, vgl. u. a. ags. ge-dyll iLuftzug" ( $<*$ tuljo-), zur Bedeutung apr, tülan ivviel»; lit. túlas smancher"; tulija- demnach sMenge«; ${ }^{140}$

(16) das Verbalsuffix -alija-, zum Teil von nominalen $l$ haltigen Stämmen ausgegangen, so. irmalija- skrank sein, erkranken« von irmala- »krank», zum Teil aber selbständig gewordenes Konglutinat, so ilalija- »begehren«, taggalijasumschliessen, umarmen«;

$\beta$ ) mit doppeltem $-l l-$ :

(17) hullija- ubekämpfen, bestreiten«, von unșicherer Etymologie, ,41 dáneben $h u l l \bar{a}$ - ds. ${ }^{142}$, wonach es sich in seinem $-l l$ - gerichtet haben kann, weiter

${ }^{138}$ Freilich ist die Urform des hethitischen Verbums doch unsicher; denn wenn van Brock, $R H A$. 22, fasc. 75, 1964, 141, Recht hat, als sie dazu das reduplizierte hali-hla-/hali-hlia- stellt, dem sie die Bedeutung " (se) prosterner beimisst, dann muss halija- einst ein Verbum der Klasse II $2 \mathrm{~b}$ gewesen sein, wodurch es als ursprünglich *hale'je- lautend zu den Fällen in III a gehörte.

139. Zu beachten ist, dass auch sonst Ausdruicke des socialen Lebens sicher ererbt sind, so z. B. pankur "Verwandtschaft, Sippe», išha- "Herrı, hašš " "Königu, so darf man nicht sofort an fremde Herkunft denken (Kronasser 170).

140 Zur genaueren Bedeutungsparallele vgl. u. a. idg. *teutä "Volk», wozu auch heth. tuzzi- "Heeri (vgl. Fn. 139) gehört, von derselben Wurzel. Freilich kann man auch mit idg. *tülo- fürs Hethitische rechnen! Dann tülija- $\doteq$ lit. tülê siMengeu $<{ }^{*} t \bar{u} l i \bar{a} ! !$

${ }^{14 .}$ Die von Hendriksen, Unters, üb. die Bed. des Heth. f. d. Laryngaltheorie 27 (zu gr. bállo usw.) ist wohl sehr anziehend, kann aber wegen des Postulates $g \mathrm{w}->h w$ - kaum richtig sein; am ehesten scheint es mir, hier an idg. "Hwel- zu denken, das zum Teil in *wel- ureissen, an sich reissen, rauben; reissen $=$ ritzen, verwunden, Wunde; töten, Blutbad usw.« (hinzuzufügen: ischlagen« im allgemeinen Sinn) bei Pokorny, $I d g . E W .1144 \mathrm{f}$. enthalten ist; ein anderer Teil muss einst nur *wel- ohne den anlautenden Laryngal gelautet haben, wie heth. walh- uschlagenu zeigt; Pokorny 1145 hat beide heth. Verba angereiht, ohne eine schärfere Scheidung vorzunehmen, die allerdings recht schwierig wäre. Oder ist heth. $h$ - diesmal sekundär? (vor urspr. *u-; hulhulija- nkämpfen» wäre in solchem Falle ziemlich jung, aber sein - $l$ - gegenïber - $l l$ - in hulla- usw. spricht dagegen, da auf Selbständigkeit von hulhulija- weisend).

${ }^{142}$ Dies Verbum braucht nicht als sekundär aus dem Paradigma eines nach der Klasse II 2 b (Friedrich, Heth. El. $\mathrm{I}^{2} \$ 173$ ) flektierten Verbums losgelöst argesehen werden, sondern kann eine Parallelform sein; doch ist seine Bezeugung recht schwach. 
hullanza- o. dgl. "Kampf" mit Zubehöro, ${ }^{143}$ die ebenfalls für ein $j$ - loses und doppeltes - $l l$ - enthaltendes Verbum zeugen; vgl, dagegen mit einfachem $-l$ das mehr selbständige reduplizierte hulhulija- kkämpfenu!

(18) das verbale suffixkonglutinat allija-, wohl immer mit nominalen Bildungen, die ein -ll-Suffix enthalten, in Verbindung stehend, so sicher katta hattallija " mit der Keule niederschlagen" zu hattalla- "Keule», und somit unter dem Einfluss der nominalen Grundlage zu seinem -ll- gelangt;

(19)-(19a) etymologisch unklar: šallija- "zergehen, schmelzen", tallija"(Götter) anrufen, anflehen", demnach in keiner Richtung verwertbar;

6. die intervokalische Lautgruppe $-r j$ :

a) mit einfachem $-r$ :

(20) arija- ydurch Orakel feststellen, zum Gegenstand einer Orkelanfrage

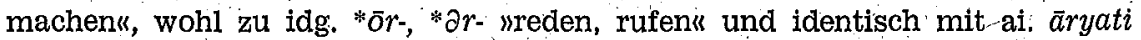
upreistu oder mit einer verwandten Form mit Reduktionsstuffe der Wurzel, die in serb. oriti se wwiderhallenu vorliegen kanin;

(21) karija- izudecken, verhüllen, verstecken", wahrscheinlich aus idg. *k'wor-jejo- zu heth. kur-k- naufbewahren, zurlickbehalten«, čop, SiR. Lingu. 9, 1956, 20 ff.; vgl auch karija- unter Nr: 4;

(22) turija- wanschirren, anspannen", denominativ zu ai. dhur- wanschirwerki; ${ }^{144}$

(23) das Verbalsuffix -arija- und -urija-, teilweise von den Nominalstämmen auf -ar- und -ur-ausgegangen, so nahšarija- usich fürchten" zu *nahšarin nahšaratt; iFurcht, Ehrfurcht" und nahšarnu- sin Furcht setzen, erschreckenu, kururija " feindlich sein" zu kurur- "feindlich, Feind, Feindschaft", teilweise als selbstänđiges Konglutinat ausgelöst, so im primären šupparija"sschlafen" neben šupp- ds. oder im denominativen gimmandarija- vïberwintern « zu gimmant- "Winter";

(24) etymologisch unklar: tarija- "sich bemühen, sich anstrengen";

B) mit doppeltem $-r r$ :

(25) marrija- szerstikckeln, zerkleinernแ, mit schwieriger Flexion, vgl. Med. marretta, marritta und Part. marrant- (was vielleicht für eine ursprünglich nach šarra- usw. gehende Flexion spricht);

(26) sonst nur neben einfachem $-\gamma$ - in demselben Paradigma: taparrijaneben taparija- "bestimmen, anordnen" und "Befehl, Befehlsgewalt, Befehlsbereich", mehr sporađisch mit -rr- neben gewöhnlich mit $r$ - geśchriebenen

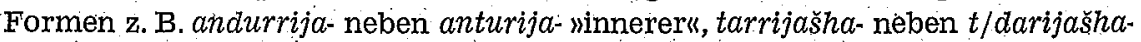
"Ermüdung"; auch diese sind kaum beweiskräftig, denn taparija- kann als

${ }^{143} \mathrm{Zu}$ solchen Bildungen zuletzt Kronasser $198 \mathrm{ff}$, der natlirlich churritische Herkunft annimmt, aber nicht beweist.

144 Das Beispiel bleibt, wenn man auch an indischer Herkunft und nicht ursprachlicher Provenienz von tur festhält, wie dies Kronasser noch immer tut (S. 144); denn nach Kr. selbst muss das Wort schon lange im Hethitischen eingebuirgert sein, worauf auch die - im Iridischen nicht belegte! - Bildung mit denominativem - $j a$ - weist; so kann es auch an unserer Lautregel beteiligt gewesen sein. 
Ableitung von tapar wleiten, verwalten, regieren unter orthographischem Einfluss desselben gestanden sein ( $t a-p a ́ r$ - eingeführt für ta-pa-), anturijakann von andurza usw. "darin, drinnen, im Innèrn " beeinflusst sein usw. ${ }^{145}$

Dass das unmittelbar folgende $-j$ - wirklich die Einfachschreibung des vorausgehenden Konsonanten bewirkte, scheint aus dem Umstand deutlich hervorzugehen, dass in vielen Fällen der fragliche Konsonant doppelt gesćhrieben wird, sobald die konsonantische Form des $-j$ - durch vokalische $(-i=)$ ersetzt wird oder das $-j$ aus morphologischen Gründen überhaupt verschwindet: so steht neben dem normal mit einfachem $-n$ - geschriebenen anija- Nr. 7 sein Iterativum annišk- (annešk-) mit normal doppeltem -nn-, weiter aber gehört dazu noch anna-nu- wunterrichten, ausbilden, (Tiere) dressieren« mit seiner Sippe; ${ }^{146}$ ähnlich könnte man auch nahšarrišk-, Iterativum zu nahšarijaNr. 23, und ešharrešk - wbluten, mit Blut besudeIn», Iterativum zu einem *ešharija-, beurteilen, obwohl hier auch andere Möglichkeiten für die $\mathrm{Er}^{-}$ klärung von $-r r$. vorhanden sind. ${ }^{146} a$

Man kann demnach kaum um die Feststellung umhin, dass vor unmittelbar nachfolgendem Konsonant -juch nach kur. zen Vokalen aller Farben, nicht nur nach e-, die hier untersuchten sechs Konsonanten einfach geschrieben werde $n$; etwaige Ausnahmen erklären sich schon wieder entweder als lautliche oder gar nur orthographische Angleichungen an daneben stehende $j$-lose Formen bzw. Bildungen derselben Wortsippe; nur die Nr. 4, vielleicht auch die Nr. 3, können dađurch nicht aus der. Welt geschaffen werden: augenscheinlich eine weitere Folge ganz besonderer lautlichen Auswirkung des Sibilants (vgl. oben Pkt, a gegen Ende!). Die lautliche und orthographische Behandlung der $j$-Gruppen kann man weiter mit derjenigen der $w$-Gruppen (oben Pkt. II) vergleichen: es besteht zwischen diesen zwei Erscheinungen eigentlich ein vollständiger Parallelismus ! ${ }^{146} \mathrm{~b}$

IV. Es ist nun an der Zeit, sich noch e in m a 1 nach den Verhältnissen, die im Kapitel C in der Entwicklung und Schreibung der in. dogermanischen Mediae aspiratae festgestellt wurden, umzusehen. Wir haben dort folgende Regeln erkannt:

1. nach historischem $-e$ - immer einfach geschrieben;

2. nach anderen Vokalen beide Möglichkeiten.

${ }^{145}$ Also an-tu-u-ri-ja- nach an-dur-za zu an-dur-ri-ja- (auch an-dur-ja-!). Auch tarrijašha- kann so erklärt werden: denn daneben steht tarra- mmüde werdenı und tarra-nu- »ermüden«! Vgl. im Text Pkt. III b am Ende zu ähnlichen Verhältnissen in der Sippe von anija-. Weiteres im Kapitel I.

${ }^{146}$ Zur Etymologie der ganzen Sippe s. die Fn. 133.

${ }^{146} \mathrm{a}$ Ein weiteres interessantes Beispiel mit solchen kombinatorischen Oppositionen in der F́n. 145.

${ }^{146} \mathrm{~b}$ Doch gilt dies nur für die Behandlung von den hier untersuchten sechs Konsonanten $(s, h, n, m, l, r)$ und von den idg. Mediae aspiratae; für die Gruppe Tenuis $+w$ gilt andere Regelung als für Tenuis $+j$, vgl. oben Kapitel $\mathbf{B}$, Pkt. II a und $I \mathrm{~b} 2$. 
Die erstere Regel ist derjenigen über die Schreibweise von $s, h, n, m, l$ und $r$ nach historischem e- ganz parallel (wenn wir die Hälfte der $s$-Belege ausschliessen, die Doppelschreibung ausweisen). Diese zwei parallelen Regelungen stlitzen einander und stellen sicherlich Auswirkung derselben laut. geschichtlichen Tendenzen dar, worüber im Kapitel $\mathrm{E}$ und J.

Die lose Regelung der Schreibung von einstigen Mediae aspiratae nach anderen Vokalen als $-e$ - kann aber jetzt auch einer erneuten Prüung unterzogen werden und mit Hilfe der Feststellungen, die in dem Kapitel D Pkt. I $\mathrm{b}-\mathrm{d}$, II und III $\mathrm{a}$ und $\mathrm{b}$ gemacht wurden, können nun auch hier schärfere und straffere Formulierungen herausgearbeitet wérden. Von den in Frage stehenden Belegen der Mediae aspiratae stehen:

a) nach einem indogermanischen langen Vokal ( $" \bar{e}$ und $i$-Diphthonge ausgenommen):

dapija- Nr. 6, wenn aus idg. *dhābh-jo-s, vgl. Fn. 51;

mīti-, mitta- Nr. 13, vgl. entweder sl. mëdb oder sak. mïjü-jüna-; 147 .

b) nach einem indogermanischen kurzen unbetonten Vokal ("e ausgenommen):

$a p \bar{a}-$ Nr. 7 , vgl. einerseits die Betonung der idg. Adjektiva auf *-bho-, andrerseits die sehr häufige Plene-Schreibung der zweiten Silbe von apāa, die es wahrscheinlich macht, dass noch in der historischen Zeit die zweite Silbe dieses Pronomens betont war; ${ }^{148}$

kuwa-pi Nr. 8, vgl. die Akzentstelle in ai. a-bhi sum, zuu, idg. demnach * qwo-bhí oder * $q$ wo-bhéi;

ateš Nr. 12, vgl, ags. adosa, adesa mit ursprünglichem Akzent vor -s-;

tagan Pkt. I c 2, idg. wohl *dheg'hom, mit bekannter Stellung des Akzents im Lok. Sg., zu beachten schon wieder die Plene-Schreibung der letzten Silbe; ${ }^{148}$

hukanzi usw. ebda., Schwundstufe zu huek- Nr. 15 und 16 enthaitende Formen; die einst sicher auf Suffixen betont waren;

c) vor $-j \cdot$ :

nur das schon erwähnte dapija- Nr. 6, falls aus idg. *dhabh-jo-s mit kurzem $-a$ - und $=$ sl. dobl'b;

d) hinter ursprïnglich kurzen betonten vokalen (ausser * $e$ ):

huppara- (doch neben hüpara-) Nr. 17, idg. ${ }^{*} H u ̈ b h(e)$ ro/ä- mit Zurückziehung des Akzentes im Substantivum;

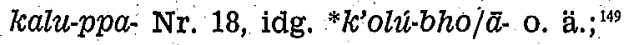

patta- Nr. 19, ein Verbaltypus wie die Formen in der Fn. 97, vgl. noch im Text, Kapitel D, Pkt. III a am Ende (Pkt. 1, 1. Absatz);

die Endungen -dduma, -ddumat(i) Nr. 21, wo man in vielen verben Akzentstelle unmittelbar davor vermuten dairf;

147 Das hethitische Wort muss idg, * $\vec{i}$ - enthalten, was direkt zum sakischen stimmt bzw. Schwundstufe zum langen Diphthong im slavischen Wort darstellt.

${ }^{148} \mathrm{Zu}$ solchen Resten der uralten Betonungsweise vgl. Fn. 118. Weiteres im Kapitel E.

${ }^{149}$ Kann auf einer frühen Tonzurückziehung bèruhen, bzw. von einem * $k^{\prime}$ olz abgeleitet sein. 
šakkurija- (seltener šakurija-) Nr. 22, zu ai. sáhuri- und somit unter dem Einfluss der verschollenen nominalen Grundlage;

hukkišk- Nr. 23 kann entweder sekundär auf der Wurzel betont gewesen sein ${ }^{150}$ oder aber ist sein $-k k$ - dem Einfluss von $-s k$ - zu verdanken; ${ }^{151}$

e) hinter ursprünglich kurzem Yokal, aber vor vermeintlichem '-w-s.

$d u$-dduwarant-, du-dduwareš- Nr. 20, reduplizierte Bildungen, wohl relativ jung, doch wohl sicher den Erscheinungen hinter der Reduplikation im Kapitel D, Pkt. I a am Ende ganz parallel behandelt, was die Doppelschreibung von $-d d$ - anbelangt, freilich gegen die Regel von der Einfachschreibung vor - $w$. verstossend, vgl. hier Pkt. II; doch ist es wohl mit speziellen Umständen um die "Laut «folge -war- zu rechnen! $!^{152}$

Die Utbersicht hat gezeigt, dass es bei den indogermanis chen Mediae aspirataefolgende Schreibregeln gibt:

1. Einfachschreibung

a) nach historischem e-;

B) nach ursprünglich langen Vokalen;

y) nach ursprünglich unbetonten kurzen vokalen, von *e abgesehen;

o) vor dem konsonant $-j$;

8) es fehlen nur Beispiele für die Stellung vor -w-, wenn wir dudduwarals gesprochenes duddor- ansehen; ${ }^{152}$ a es kann dann erwartet werden, dass einmal auch hier Beweise für Einfachschreibung auftauchen;

2. Doppelschreibung

a) hinter kurzen ursprünglich betontenvokalen (*e ausgenommen);

$\beta)$ vor sk- (vgl. Fn. 151)?

Vergleicht man nun diese Regeln mit denjenigen, die die Schreibweise der in diesem Kapitel behandelten sechs Laute im allgemeinen bestimmen, so erkennt man, dass zwischen beiden seiten ein vollständiger Parallelis m us bes teht, ein Resultat, wodurch alle hier vorgebrachten Folgerungen besonders stark gestiutzt werden. Freilich ist das Material hie und da zu gering, um ganz sichere Schlüsse daraus zu ziehen; ich kann aber schon jetzt hervorheben, dass es noch unveröffentlichte Etymologien gibt, die meine Behauptungen bedeutend näher der Sicherheit bringen.

${ }^{150}$ Parallel mit hašsik-, tiššakk- und tiššikk-oben Pkt. III a?

${ }^{151}$ Dann gehört es als ein gesprochenes $h u k k s k$ - zu den Fällen oben im Kapitel A am Ende (wakkišk-) und Kapitel B, Pkt. II a 3 Nr. 3 a (akkušk-).

Vgl. jedoch annišk-usw. oben S. 39!

152 Vgi. in diesem Kapitel, Pkt. II Nr. 15 und Fn. 114, auch Fn. 111. Es wird sich aber eines Tages herausstellen, dass die Wirkung des kurzen Reduplikationsvokals (vgl. im Kapitel $\mathbf{E}$ und $J$ ) auf den folgenden Konsonant stärker war denn die von etwaigem reellem $-w$; ähnlich wirkt sich die Reduplikation oben Pkt. I a) aus, wenn ne-nna-, me-mma- und me-mmal die ursprünglichen Verhältnisse wiederspiegeln? Weiter im Kapitel I.

${ }^{152}$ a Vgl. auch die vorige Anm:! 
Hier nur ganz kurz noch zu Un regelmässigkeiten in der Schreibung von -s- $\mathrm{nach}-\dot{e}-\mathrm{Vokal}$ (das vorliegende Kapitel, Pkt. I a Nr. 12-27): in allen kontrollierbaren Fällen ist dies $-e$ - in der Ursprache als kurz anzusehen; und im Lichte der eben dargestellten Regeln ist dieser Uimstand noch klarer geworden, man muss freilich nur annehmen, dass das kurze *-e- nur auf -s- dieselbe Wirkung ausübte wie die übrigen kurzen Vokale; da nun Doppelschreibung der indogermanischen Mediae aspiratae und von $s, h, n, m, l, r$ oben als nur nach kurzen in der Ursprache b e to n te $n$ Vokalen regelrecht erwiesen wurde, muss man untersuchen, ob dies bei den Fällen mit -ešš- für idg. "es- zutrifft; tatsächlich gibt es nur zwei Wörter, wo man diese Akzentuierung auf den ersten Blick abweisen mag; das sind


die Schwierigkeit umgehen; wenn man bedenkt, a) dass beide Verba eigentlich junge Substitute fïr Wurzelpräsentien auf thematischen Vokal e/o- sind und b) dass man in einem dreisilbigen Stamm wie *qesājé- wohl auch mit einem Nebenakzent auf der ersten Silbe rechnen darf. ${ }^{153}$ Man kann demnach die unregelmässige Doppelschreibung von -s- nach $e$-Vokal auf die Stellung nach einem indogermanischen kurzen und betonten (oder mindéstens nebentonigen) *-e- beschränken. ${ }^{154}$ Eine gute Bestätigung bekommt diese Regel von der Seite des Paares nepiš- "Himmel" (hier Pkt. I a Nr. 7) - ateš- "Beil" (Kapitel C Nr. 12): das erstere geht auf idg. *nébhes- zurück, sein Suffix *eswar sicher unbetont, daher die Einfachschreibung des $s$-Lautes; das zweite geht nach Ausweis von ags. adosa, adesa auf idg. *adhés- zurick, sein Suffix war demnach betont, daher die Doppelschreibung in den Kasus obliqui (Akk. Sg. ateššan, Instr. ateššit) ${ }^{155}$

(Fortsetzung folgt im nächsten Heft.) :

${ }_{153}$ Dasselbe kann auch in anderen $\bar{a}$-Verben beobachtet werden, vgl. hulläFn. 141 und 142, munna- wverhüllen, verstecken« u. a.

154 Wobei freilich die Pflicht übrig bleibt, dass für andere 's-Wörter mit einfachem - $\varsigma$ - nach ursprachlichem kurzem *e andere Betonung erwiesen werden soll; das ist für eš- ısein« Nr. 1 und šeš- mruhen, schlafen« Nr. 4 wohl ganz gangbar, denn hier drang ja die Vollstuffe auch in Formen mit Endbetonung, woraus dann spezielle Aussprache des $-s$-auch in wurzelbetonte Formen eindringen konnte.

Man darf weiter noch einige andere Faktoren, die an der Einfachschreibung von -s- schuld sein können, nennen: a) in Prät. 1. Sg. ešun usw. kann das idg. Imperfekt ${ }^{*} \bar{e} s-(m i t$ Augment!)-stecken; in Prät. 3. Pl. ešir wohl das idg. Perfekt, etwa *ēs-ēr; demnach das einfache $-s-$ hier überall ganz richtig; b) -sw- in éšuen "wir waren«, šešueni wẃir schlafen« usw:, Verbalsubst. ešuwar, šešuwar, Inf. I కešuwanzi muss ebenfalls in Ordnung sein, s. Pkt. II! c) 3. Pl. aš-anzi, šašañzi, ašandu, *šašandu, Part. ašant-, šašant- haben wiederum wohl lautgesetzliches einfaches -s-, s. Pkt. III a!

155 Zuletzt uiber dies Wort Kronasser 328. 